\title{
The INALT family - a set of high-resolution nests for the Agulhas Current system within global NEMO ocean/sea-ice configurations
}

\author{
Franziska U. Schwarzkopf ${ }^{1}$, Arne Biastoch ${ }^{1,2}$, Claus W. Böning ${ }^{1,2}$, Jérôme Chanut ${ }^{3}$, Jonathan V. Durgadoo ${ }^{1}$, \\ Klaus Getzlaff ${ }^{1}$, Jan Harlaß ${ }^{1}$, Jan K. Rieck ${ }^{1}$, Christina Roth ${ }^{1}$, Markus M. Scheinert ${ }^{1}$, and René Schubert ${ }^{1}$ \\ ${ }^{1}$ GEOMAR Helmholtz Centre for Ocean Research Kiel, Düsternbrooker Weg 20, 24105 Kiel, Germany \\ ${ }^{2}$ Kiel University, Christian-Albrechts-Platz 4, 24118 Kiel, Germany \\ ${ }^{3}$ Mercator-Ocean, Parc Technologique du Canal, 8-10 rue Hermès, 31520 Ramonville Saint-Agne, France
}

Correspondence: Franziska U. Schwarzkopf (fschwarzkopf@geomar.de)

Received: 6 December 2018 - Discussion started: 6 February 2019

Revised: 19 June 2019 - Accepted: 21 June 2019 - Published: 29 July 2019

\begin{abstract}
The Agulhas Current, the western boundary current of the South Indian Ocean, has been shown to play an important role in the connectivity between the Indian and Atlantic oceans. The greater Agulhas Current system is highly dominated by mesoscale dynamics. To investigate their influence on the regional and global circulations, a family of high-resolution ocean general circulation model configurations based on the NEMO code has been developed. Horizontal resolution refinement is achieved by embedding "nests" covering the South Atlantic and the western Indian oceans at $1 / 10^{\circ}$ (INALT10) and $1 / 20^{\circ}$ (INALT20) within global hosts with coarser resolutions. Nests and hosts are connected through two-way interaction, allowing the nests not only to receive boundary conditions from their respective host but also to feed back the impact of regional dynamics onto the global ocean. A double-nested configuration at $1 / 60^{\circ}$ resolution (INALT60) has been developed to gain insights into submesoscale processes within the Agulhas Current system. Large-scale measures such as the Drake Passage transport and the strength of the Atlantic meridional overturning circulation are rather robust among the different configurations, indicating the important role of the hosts in providing a consistent embedment of the regionally refined grids into the global circulation. The dynamics of the Agulhas Current system strongly depend on the representation of mesoscale processes. Both the southward-flowing Agulhas Current and the northward-flowing Agulhas Undercurrent increase in strength with increasing resolution towards more realistic values, which suggests the importance of improving mesoscale dynamics as well as bathymetric slopes along this
\end{abstract}

narrow western boundary current regime. The exploration of numerical choices such as lateral boundary conditions and details of the implementation of surface wind stress forcing demonstrates the range of solutions within any given configuration.

\section{Introduction}

The waters around southern Africa are an important player in the world-wide system of ocean currents. The Agulhas Current (AC), one of the strongest currents in the world ocean, is the western boundary current in the South Indian Ocean and has a far-reaching influence into the Atlantic (Gordon, 2003; Lutjeharms, 2006). Forced by trade winds, it transports warm and saline water from the tropical Indian Ocean along the African coast towards the southern tip of Africa, where it performs an abrupt turn back into the Indian Ocean. Due to the termination of the African continent at around $35^{\circ} \mathrm{S}$ and a range of non-linear processes, a part of the $\mathrm{AC}$ finds its way into the South Atlantic. It thus provides an important link for the surface limb of the global overturning circulation from the Pacific and Indian oceans into the Atlantic Ocean (Durgadoo et al., 2017; Le Bars et al., 2013; Beal et al., 2011). Modelling the AC system and its embedment within the global circulation demands for global ocean general circulation models with mesoscale resolution in the region around southern Africa (e.g. Biastoch et al., 2008a; Holton et al., 2017) 
The northern part of the $\mathrm{AC}\left(27\right.$ to $\left.34^{\circ} \mathrm{S}\right)$ flows relatively stably and close to the continental slope (Lutjeharms, 2006). Further south at around $34-35^{\circ} \mathrm{S}$ the shelf begins to widen and allows the AC to meander. Due to inertia, the current overshoots the African continental edge at $20^{\circ} \mathrm{E}$ before it abruptly retroflects back into the Indian Ocean. There it continues as the Agulhas Return Current and closes the subtropical gyre (Lutjeharms and Ansorge, 1997). The dynamics of the retroflection are an interplay between the wind forcing, inertia, bathymetry and non-linear dynamics (see box 1 in Beal et al., 2011). At the retroflection itself, mesoscale eddies are shed (Pichevin et al., 1999; van Leeuwen et al., 2000) that interact, merge and split in the Cape Basin (Boebel et al., 2003; Laxenaire et al., 2018). With diameters of up to $500 \mathrm{~km}$ (Arhan et al., 1999) and average depth extensions of $2000 \mathrm{~m}$, eventually reaching down to the bottom (van Aken et al., 2003), Agulhas rings are among the largest mesoscale features in the world ocean, transporting large amounts of warm and saline Indian Ocean water into the relatively colder and fresher South Atlantic (Gordon, 1986).

Upstream the AC, in the Mozambique Channel and southeast of Madagascar, mesoscale eddies are also formed through local instabilities (Swart et al., 2010). These propagate into the western boundary current system, causing the AC to sometimes meander off-shore (de Ruijter et al., 1999b). These so-called Natal Pulses exhibit timescales of 70 to $90 \mathrm{~d}$ and rapidly propagate downstream. They imprint a range of spatiotemporal scales on the AC that may impact the generation and fate of Agulhas rings (Rouault and Penven, 2011; Schouten et al., 2002).

Due to the open setting in the Atlantic, Indian and Southern oceans, the AC system forms a bridge between the winddriven circulation in the individual basins. It effectively is a key link in the Southern Hemisphere supergyre, combining both subtropical gyres of the Indian and the Atlantic oceans (Speich et al., 2007). The amount of Indian Ocean water that flows through the AC system and becomes part of the Atlantic circulation is termed Agulhas leakage (Gordon, 2003). A portion of this finds its way into the upper limb of the Atlantic meridional overturning circulation (AMOC) (Rühs et al., 2013). The continuous inflow of Agulhas leakage influences the hydrography and water-mass distribution in the Atlantic Ocean (Lee et al., 2011; Lübbecke et al., 2015; Biastoch et al., 2015). The amount of Agulhas leakage (and hence the influence on the Atlantic Ocean) is linked to atmospheric processes, more specifically the Southern Hemisphere westerlies on decadal timescales (Durgadoo et al., 2013). As part of a decadal upward swing, the Agulhas leakage was subject to a $30 \%$ increase from the 1960s to the 2000s (Biastoch et al., 2009b; Biastoch et al., 2015).

The role of the AC system in the surface limb of the overturning circulation is mirrored at depth by a flow of deep water masses through the AC system. Arhan et al. (2003) showed that around $11 \mathrm{~Sv}$ of North Atlantic Deep Water finds its way around the southern tip of Africa from west to east.
While most of it is subject to a sluggish flow into the deep basins east and west of the Madagascar Ridge, it is also found in a northward-flowing core beneath and in-shore of the AC (Casal et al., 2006). This Agulhas Undercurrent (AUC) is also subject to strong variability as a consequence of the interplay between Natal Pulses and the western boundary current regime (Beal, 2009; Biastoch et al., 2009a).

Model simulations have been increasingly successful in capturing the AC system over the past decades. In models with relatively coarse resolution below the first baroclinic Rossby radius (Chelton et al., 1998), the AC follows Sverdrupian dynamics and is able to perform its retroflection back into the Indian Ocean (de Ruijter et al., 1999a). Agulhas rings begin to appear at resolutions of $1 / 3$ to $1 / 4^{\circ}$; however, they are too regular in size and pathways. Resolutions of about $1 / 10^{\circ}$, representing the Rossby radius of deformation in this region, are required to simulate the instability processes in the source regions of the $\mathrm{AC}$ as well as along the $\mathrm{AC}$ path (Natal Pulses) and to provide the correct current structure of the western boundary current, including the AUC (Biastoch et al., 2009a). It still remains to be explored whether a horizontal resolution of $1 / 10^{\circ}$ is already sufficient to simulate the full range of mesoscale processes and whether integral numbers like Agulhas leakage depend on the previously unrepresented dynamics. This is in particular the case once submesoscale dynamics are included in the simulation, as has been shown for the Gulf Stream and the successional North Atlantic Current by Chassignet et al. (2017).

Despite locally resolving mesoscale dynamics, as can be achieved by regional models (e.g. Penven et al., 2006; Hermes et al., 2007), capturing Southern Ocean dynamics, that have an impact on the Agulhas leakage (Durgadoo et al., 2013), might also be necessary to realistically simulate the dynamics of the AC system. To study the impact of the largescale circulation on the AC or the impact of the AC system on the global overturning, global models are required. However, the numerical costs of global mesoscale resolving models are still too high to perform several multi-decadal experiments. To overcome this conflict, nesting has been shown to provide a good compromise, allowing for regional high resolution and keeping the global context (Biastoch et al., 2018).

To address the abovementioned questions, a systematic hierarchy of model configurations based on the Nucleus for European Modelling of the Ocean (NEMO) code, ranging from eddy-poor to eddy-rich configurations has been developed and is described here. Therein, the flagship configuration INALT20 (Fig. 1) covers the South Atlantic and the western Indian oceans, including the AC system and a Southern Ocean sector at mesoscale resolution $\left(1 / 20^{\circ}\right)$. Configurations at coarser $\left(1 / 10^{\circ}\right)$ resolution, INALT10 and INALT10x, serve three purposes: they provide the comparison with previous configurations and the possibility to couple to an active atmosphere, and enable the systematic evaluation to explore the influence of Southern Ocean dynamics. Un-nested versions of the host configurations at $1 / 2^{\circ}$ (ORCA05) and $1 / 4^{\circ}$ 


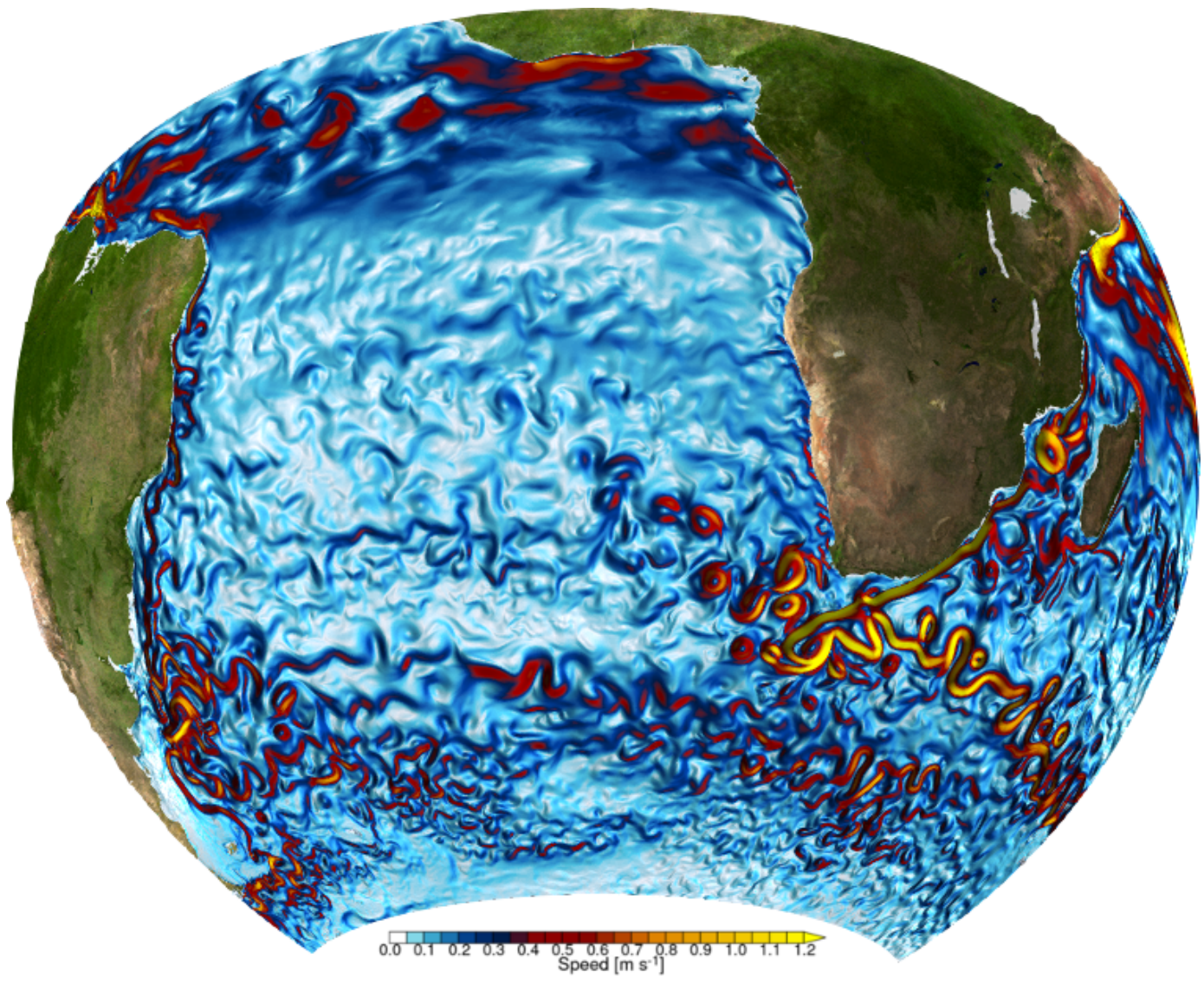

Figure 1. Snapshot of surface speed (in $\mathrm{m} \mathrm{s}^{-1}$ ) as simulated in the nested area of INALT20.

(ORCA025) provide a comparison of the high-resolution configurations to coarser global ocean models, e.g. being performed for longer timescales or in coupled simulations. Additionally, on the other end of the range in resolution, a secondary nest at $1 / 60^{\circ}$, INALT60, allows to explore the role of submesoscale dynamics in the AC system. With this set of model configurations, resolution convergence within the Agulhas system is investigated.

\section{The INALT family}

The INALT ${ }^{1}$ family is a set of global ocean model configurations covering the greater $\mathrm{AC}$ system at high resolution. The predecessor of these configurations is INALT01 (Durgadoo et al., 2013), a well-established $1 / 10^{\circ}$ model configuration. INALT01 has been widely used to understand AC dynamics (Rühs et al., 2017; Malan et al., 2018), the effect of the Southern Hemisphere wind systems on the AC (Durgadoo et al., 2013; Loveday et al., 2014), the impact of Agulhas

\footnotetext{
${ }^{1}$ The name INALT was introduced by Durgadoo et al. (2013) as an acronym for "inaliti", meaning needle in isiXhosa. "Agulhas" is Portuguese for needles. INALT can also be read as "INdianAtLanTic".
}

leakage on the Atlantic circulation and hydrography (Biastoch et al., 2015; Lübbecke et al., 2015), as well as local phenomena in the (greater) Agulhas region (Cronin et al., 2013; Malan et al., 2019), and has been utilized for a range of interdisciplinary applications (Scussolini et al., 2013; Steinhardt et al., 2014; van Sebille et al., 2015). The set of configurations described here updates INALT01 with respect to the code version. Additionally, the nested region is extended into the Southern Ocean and a range of resolutions is covered.

\subsection{Configurations}

The configurations introduced in this study are based on the ocean general circulation model NEMO (version 3.6; Madec and the NEMO team, 2014) coupled to the Louvain-LaNeuve sea-ice model version 2 using a viscous-plastic rheology (LIM2-VP; Fichefet and Maqueda, 1997). Global configurations with tri-polar Arakawa-C grids, named ORCA, are used as a basis to build regionally finer resolved configurations realized by the AGRIF (Adaptive Grid Refinement in Fortran) library (Debreu et al., 2008). Hereby, a global, relatively coarsely resolved grid (hereafter "host") is combined with a regionally confined, high-resolution grid (hereafter "nest") allowing for two-way interactions: the host not only 
provides boundary conditions for the nest but also receives information from the nest. AGRIF is a very cost-effective technology to regionally refine the horizontal grid, with typically just $10 \%-20 \%$ computational overhead through the global host (Biastoch et al., 2018), depending on the size of the nested region: the bigger, the less overhead.

The model solutions on the host and nest grids are integrated sequentially. Once the model is advanced by one time step on the host grid, the solutions of two consecutive time steps are temporally and spatially interpolated to the nest grid and the corresponding finer time steps. Given these boundary conditions, the model is advanced by several time steps on the nest grid until the same time as on the host grid is reached. Afterwards, the barotropic solution (i.e. sea level and barotropic fluxes) on the host grid is updated with the solution from the nest grid along its boundaries. This is repeated for a certain number of time steps after which the solution on the host grid is updated with the solution on the nest grid everywhere inside the refined domain (baroclinic update; Debreu et al., 2008).

The flagship configuration INALT20 consists of a host at $1 / 4^{\circ}$ horizontal resolution and an embedded nest at $1 / 20^{\circ}$ resolution (Fig. 1), covering the South Atlantic and the western Indian oceans between $70^{\circ} \mathrm{W}$ and $70^{\circ} \mathrm{E}$ and from the northern tip of the Antarctic Peninsula at $63^{\circ} \mathrm{S}$ to $10^{\circ} \mathrm{N}$ (Fig. 2). Analogously, INALT10x covers the same nested region but at $1 / 10^{\circ}$ and embedded within a host at $1 / 2^{\circ}$. With the southern boundary located further north, at $50^{\circ} \mathrm{S}$, INALT $10 \mathrm{cov}-$ ers the same nest area as the predecessor (INALT01; Durgadoo et al., 2013). INALT10, on the one hand, allows to directly compare the old and the new versions of this configuration, and on the other hand allows to elucidate the influence of mesoscale dynamics in the Atlantic portion of the Antarctic Circumpolar Current (ACC) by direct comparison with INALT10x, in which this region is represented at eddying resolution. To shed light on submesoscale processes around the southern tip of the African continent, INALT60 is introduced with a secondary $1 / 60^{\circ}$ nest ( 0 to $40^{\circ} \mathrm{E}$ and 45 to $25^{\circ} \mathrm{S}$ ), embedded within a spatially reduced $1 / 20^{\circ}$ nest version INALT20r $\left(20^{\circ} \mathrm{W}\right.$ to $70^{\circ} \mathrm{E}$ and 50 to $\left.6.5^{\circ} \mathrm{S}\right)$. The sizes of the different configurations and computational costs required to simulate one model year are given in Table 1 . In INALT10 and INALT60, the sea-ice model is only performed on the host grids, as ice does not enter the nested domain, while in INALT10x and INALT20 sea ice is also represented on the refined grid. Additionally, the global grids ORCA025 (1/4 ${ }^{\circ}$ horizontal resolution; Barnier et al., 2006) and ORCA05 $\left(1 / 2^{\circ}\right.$ horizontal resolution; Biastoch et al., 2008b) also exist as un-nested versions and are used to decipher the influence of the mesoscale processes onto largescale ocean dynamics by isolating the nest effect outside the nest regions (e.g. Biastoch et al., 2008a).

The horizontal resolutions of these configurations for the greater AC system translate into grid sizes of 40 and $20 \mathrm{~km}$ within ORCA05 and ORCA025, respectively, via 8 and $4 \mathrm{~km}$ within INALT10(x) and INALT20(r), respectively, to less than $2 \mathrm{~km}$ within INALT60 (Fig. 2). In the eddy-poor configuration (ORCA05), mesoscale effects are parameterized following Gent and McWilliams (1990). ORCA025 is eddy active since it resolves the first baroclinic Rossby radius at midlatitudes (Chelton et al., 1998). The grid sizes of the nested configurations are below this radius of $10 \mathrm{~km}$ at $\sim 55^{\circ} \mathrm{S}$ south of Africa and can therefore be referred to as "eddy rich", representing the mesoscale.

All configurations share the same vertical grid, with 46 $z$ levels varying in layer thickness from $6 \mathrm{~m}$ at the surface to $250 \mathrm{~m}$ in the deepest layers, resolving the first baroclinic mode (Stewart et al., 2017) which is needed for the representation of the major baroclinic currents. The same vertical grid has proven to be an appropriate choice for simulations with model configurations up to $1 / 20^{\circ}$ horizontal resolution (e.g. Böning et al., 2016; Behrens et al., 2017). The bottom topography is represented by partial steps (Barnier et al., 2006) with a minimum layer thickness of $25 \mathrm{~m}$. The bathymetry datasets in ORCA05 and ORCA025 have been developed within the DRAKKAR community and are described in Molines et al. (2006) and Barnier et al. (2006), respectively. For the nest grids at $1 / 20$ and $1 / 60^{\circ}$ resolution, bathymetries are interpolated from ETOPO1 and from ETOPO2 for the grids at $1 / 10^{\circ}$ using the nesting tools (Lemarié, 2006).

\subsection{Numerical settings and parameterizations}

All configurations share a range of settings described in the following. A "filtered" free surface formulation is used (Roullet and Madec, 2000) which damps fast external gravity waves. Assuming that sea surface height (SSH) anomalies are small compared to the resting depth, free surface is linearized, which translates into a fixed ocean volume in time. The vertical mixing is parameterized according to a 1.5 turbulent kinetic energy closure (Blanke and Delecluse, 1993). Static instabilities are handled by enhancing diffusivities and viscosities by a factor of 10 . Spatially varying Laplacian, iso-neutral mixing is applied to tracers, while momentum is subject to bi-Laplacian horizontal mixing. A diffusive bottom boundary layer formulation for tracers (Beckmann and Döscher, 1997), allowing a communication of two adjacent bottom grid cells at different depths levels, is active. Quadratic bottom friction is applied globally with an enhancement of a factor up to 50 to reduce the flow downstream of the Torres Strait in ORCA05 and on the host grids of INALT10(x) and additionally downstream of the Denmark Strait, and the Bab-el-Mandeb Strait in ORCA025 and on the host grids of INALT20(r) and INALT60. In the un-nested configurations, as well as on the host grids of the nested configurations, the lateral boundary condition allows for free slip, while no slip is allowed along the lateral boundaries of the oceans on the nest grids in all reference simulations. In all reference experiments, the wind stress formulation takes into account the underlying ocean surface velocities ("rel- 


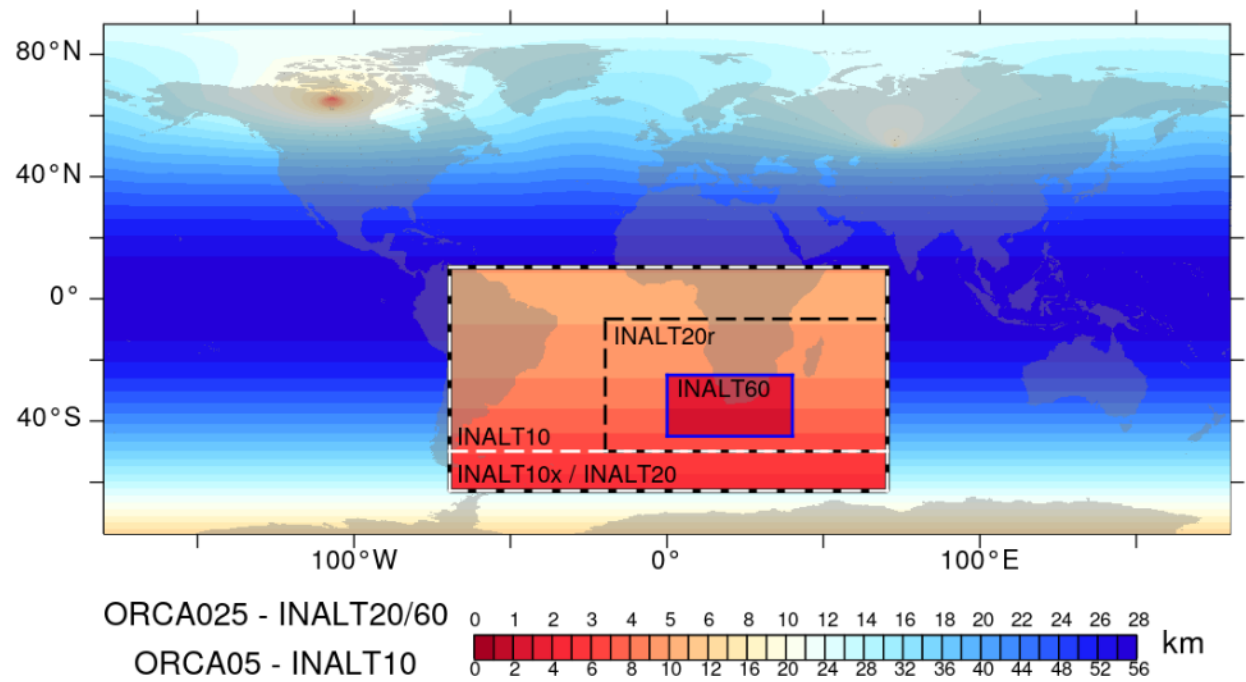

Figure 2. Grid sizes in the INALT family: shown is the zonal grid length (in km) for the global ORCA025 grid with the embedded INALT20 (outer black box), INALT20r (inner black box) and INALT60 (blue box) grids (upper scale), as well as for ORCA05 with the embedded INALT10x (white dashed box, same as INALT20) and INALT10 with its southern boundary shifted north (lower scale).

Table 1. Grid sizes, time steps for hosts (h) and nests (n1) as well as the secondary nest in INALT60 (n2), and grid point integrations per model day (GPIPD) are given for the individual configurations. The computational requirements in nodes consisting of $24 \mathrm{CPUs}$ each, for the model code itself (NEMO) and the input-output server (XIOS), and CPU hours (per model year) are estimated on a Cray XC40, equipped with Intel Xeon Haswell processors, at the North-German Supercomputing Alliance ("Norddeutscher Verbund für Hoch- und Höchstleistungsrechnen"; HLRN).

\begin{tabular}{llrrrr}
\hline Configuration & Horizontal dimension & Time step (h/n1/n2) & GPIPD & Nodes (NEMO/XIOS) & CPU hours \\
\hline ORCA05 & $722 \times 511$ & 2160 & $6.8 \times 10^{8}$ & $26(25 / 1)$ & 300 \\
ORCA025 & $1442 \times 1021$ & 1440 & $41 \times 10^{8}$ & $33(32 / 1)$ & 2200 \\
INALT10 & ORCA05 $+1404 \times 674$ & $2160 / 720$ & $59 \times 10^{8}$ & $39(37 / 2)$ & 4100 \\
INALT10x & ORCA05 $+1404 \times 924$ & $2160 / 720$ & $78 \times 10^{8}$ & $44(42 / 2)$ & 5300 \\
INALT20 & ORCA025 $+2799 \times 1839$ & $1200 / 400$ & $560 \times 10^{8}$ & $104(96 / 8)$ & 30500 \\
INALT20r & ORCA025 $+1804 \times 1024$ & $1200 / 400$ & $230 \times 10^{8}$ & $104(96 / 8)$ & 15000 \\
INALT60 & INALT20r $+2404 \times 1483$ & $900 / 300 / 100$ & $1700 \times 10^{8}$ & $146(134 / 12)$ & 121800 \\
\hline
\end{tabular}

ative winds"). For these two boundary conditions, sensitivity experiments are performed in INALT20 (see below). A second-order centred tracer advection scheme (total variance dissipation - TVD; Zalesak, 1979) is used. Momentum advection is in vector form with applied Hollingsworth correction (Hollingsworth et al., 1983). The vorticity term is formulated conserving both the potential enstrophy of horizontally non-divergent flow and the horizontal kinetic energy (EEN; Arakawa and Hsu, 1990).

The nested configurations at $1 / 10$ and $1 / 20^{\circ}$ horizontal resolution share a spatial horizontal refinement factor of 5 with respect to their host grids, which would have implied an identical temporal refinement based on Courant-FriedrichsLewy (CFL) stability considerations. A temporal refinement of 3 has however proven to be stable. For the secondary nest in INALT60, both horizontal and temporal refinement factors are 3 against the first nest. A sponge layer is applied along the boundaries of the nests that damps (according to a second-order Laplacian operator) nest and host differences. It maintains consistency between the grid solutions and filters out noise that would develop along open boundaries. As explained by Debreu et al. (2008), this is a key ingredient in the overall nesting robustness. The host grids are updated with the three-dimensional nest solution at every third host grid time step. The different model resolutions demand different parameters for the above-mentioned schemes as summarized in Table 2.

Climatological river runoff is applied, distributing fresh water input from land along the coasts and at the estuaries of the 99 major rivers (Bourdallé-Badie and Treguier, 2006). At the river mouths and at the locations where runoff enters the ocean, enhanced vertical mixing over the upper $10 \mathrm{~m}$ is applied and the sea surface salinity restoring is suppressed. Elsewhere, extremely weak sea surface salinity restoring is 
Table 2. Resolution-dependent parameters for the different configurations: eddy-induced velocity coefficient (aeiv0; in $\mathrm{m}^{2} \mathrm{~s}^{-1}$ ); horizontal eddy diffusivity coefficients for tracer (aht 0 ; in $\mathrm{m}^{2} \mathrm{~s}^{-1}$ ) and momentum (ahm0; in $\mathrm{m}^{4} \mathrm{~s}^{-1}$ ) are nominally set for the maximum grid size (which is at the Equator except for the nest grids in INALT20r and INALT60 that do not include the Equator at high resolution) and scaled with the poleward decrease of the grids sizes; lateral mixing coefficient in the bottom boundary layer (ahtbbl; in $\mathrm{m}^{2} \mathrm{~s}^{-1}$ ); sponge coefficients for tracer and dynamics (sponge; in $\mathrm{m}^{2} \mathrm{~s}^{-1}$ ). Note that ORCA05 also represents the values for the host grid in INALT10 and INALT10x; ORCA025 represents those for the host grid in INALT20, INALT20r and INALT60. The settings for the first nest in INALT60 are identical to those given for INALT20(r).

\begin{tabular}{lrrcrr}
\hline & aeiv0 & aht0 & ahm0 & ahtbbl & sponge \\
\hline ORCA05 & 1000 & 600 & $-6.0 \times 10^{11}$ & 1000 & - \\
ORCA025 & - & 300 & $-1.5 \times 10^{11}$ & 1000 & - \\
INALT10(x) & 0 & 120 & $-2.4 \times 10^{10}$ & 100 & 2700 \\
INALT20(r) & - & 60 & $-6.0 \times 10^{9}$ & 40 & 600 \\
INALT60 & - & 20 & $-6.7 \times 10^{8}$ & 4.444 & 200 \\
\hline
\end{tabular}

applied via damping in the surface freshwater flux at a pis-

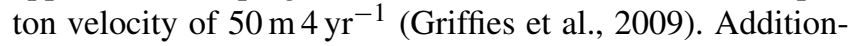
ally, Newtonian tracer damping at the outflow of the Mediterranean Sea into the Atlantic is applied to correct the unrealistically shallow spreading of the Mediterranean outflow. Damping is applied in a spherical area centred at $7^{\circ} \mathrm{W}, 36^{\circ} \mathrm{N}$, and $500 \mathrm{~m}$ depth with a horizontal radius of $1.5^{\circ}$ and a vertical extent of $1000 \mathrm{~m}$. Damping strength declines exponentially with increasing distance from the centre.

\subsection{Hindcast and sensitivity experiments}

The atmospheric forcing for all experiments described here is based on the COREv2 products and bulk formulae provided by Large and Yeager (2009). It builds on NCEP/NCAR reanalysis data merged with satellite-based radiation and precipitation, employing a set of parameter corrections to minimize global flux imbalances. The 30-year long spin-up integrations, initialized with temperature and salinity from the World Ocean Atlas (Levitus et al., 1998 with modifications in the polar regions from PHC; Steele et al., 2001) and an ocean at rest, forced by interannually varying atmospheric boundary conditions from 1980 to 2009, were performed in all configurations except for INALT60, where only 10 years from 1980 to 1989 were integrated. The ocean states at the end of the spin-up integrations are used to initialize hindcast simulations for the period 1958 to 2009. All experiments are thus performed over the same integration length, utilizing the same atmospheric forcing. The comparisons between the different configurations therefore allow to isolate the impact of different resolutions. Despite COREv2 having a spatial resolution of $2^{\circ} \times 2^{\circ}$, being relatively coarse, it was chosen as the most coherent and robust dataset available at the time of the
Table 3. To uniquely define the different model experiments, internal experiment identifiers are provided here.

\begin{tabular}{llll}
\hline Configuration & Spin-up & Hindcast & $\begin{array}{l}\text { Sensitivity } \\
\text { experiments }\end{array}$ \\
\hline ORCA05.L46 & KJH0003 & KJH0004 & \\
ORCA025.L46 & KJR36201h & KJR36216h & \\
INALT10.L46 & KJH0016 & KJH0017 & \\
INALT10x.L46 & KJH0006 & KJH0007 & \\
INALT20.L46 & KFS039 & KFS044 & KFS057 (FS_RW) \\
& & & KFS058 (FS_AW) \\
INALT60.L46 & KFS004 - & & KFS059 (FS_PW) \\
& KFS006 & & \\
\hline
\end{tabular}

model integrations to provide long (multi-decadal) hindcast simulations.

In INALT20, sensitivity experiments starting from the oceanic state at 31 December 1994 in the hindcast experiment and covering the period 1995 to 2009 are performed to test the influence of lateral and surface boundary conditions on the dynamics in the AC system, the South Atlantic and the overturning circulation. Building on the reference configuration with "no slip" on the nest grid (NS) and "free slip" on the host grid in all cases, sensitivity experiments are performed with "free slip" also in the nest (FS). Another set was performed to explore the role of ocean currents in the wind stress calculation. Compared to the original formulation as "relative wind" (RW), cases for "absolute wind" (not considering the ocean current; AW) and "partial wind" (PW) are tested. In the latter, the influence of the ocean velocity in the wind stress formulation is reduced compared to the relative wind formulation by a factor of 0.7 , consequently only taking into account $70 \%$ of the ocean currents (simplified after Renault et al., 2017). While Renault et al. (2017) use a spatially varying coefficient for the influence of ocean currents in the wind stress formulation, a constant value, representative for the AC system, is used here. Table 3 provides internal identifiers for the experiments used.

\section{Results}

The simulations described above are evaluated with respect to their general representation of mesoscale variability (Sect. 3.1). The impact of mesoscale processes on the largescale circulation is presented by the evaluation of the representation of key measures of the horizontal circulation in the South Atlantic, the western Indian and the Southern oceans (Sect. 3.2), as well as of the meridional overturning circulation in the Atlantic Ocean (Sect. 3.3). The dependence on the resolution of mesoscale processes in the Agulhas Current system itself is analysed in terms of simulating the Agulhas Current and Undercurrent (Sect. 3.4), as well as the Agulhas leakage (Sect. 3.5). 


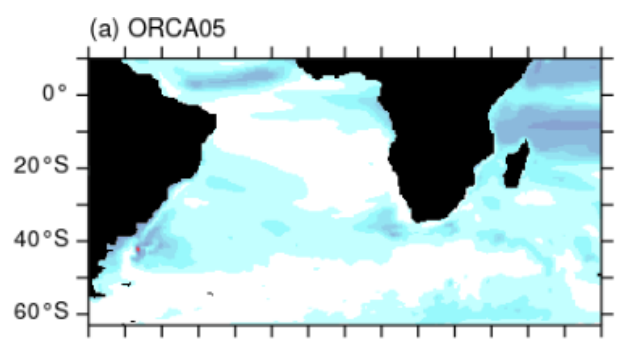

(c) INALT10x

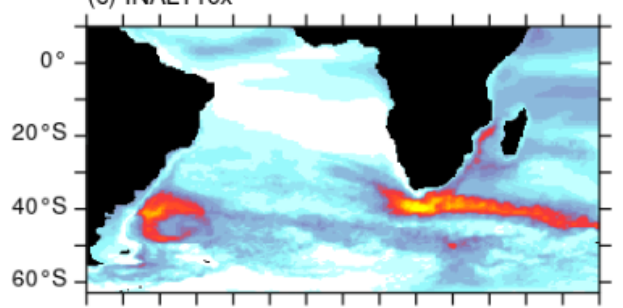

(e) INALT10
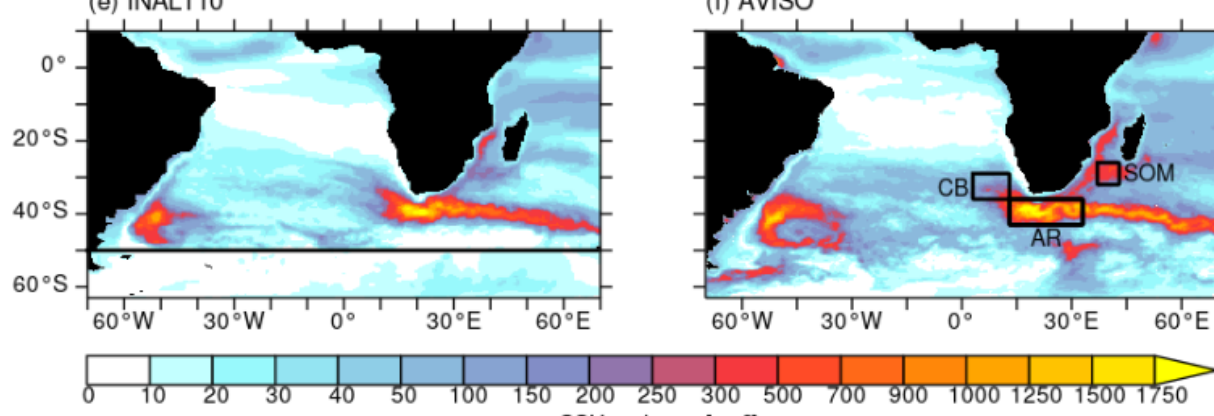

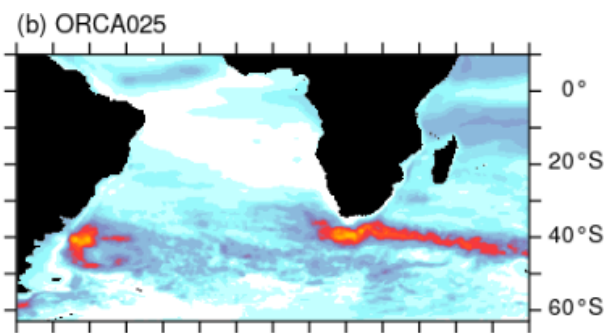

(d) INALT2O

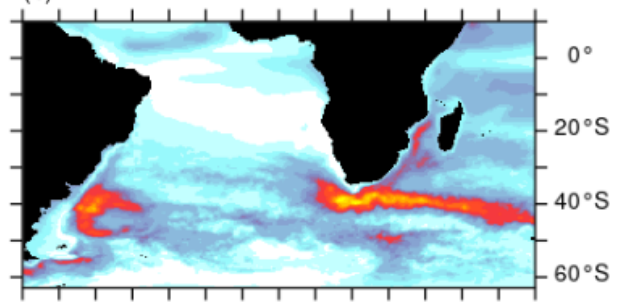

(f) AVISO

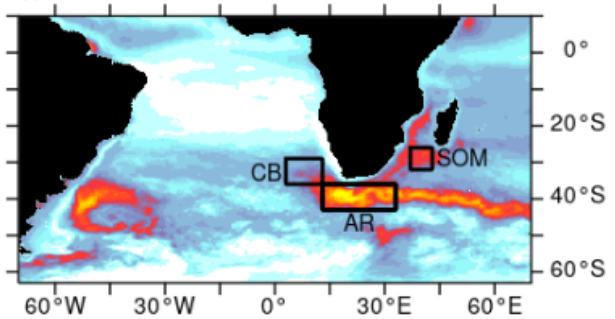

Figure 3. SSH variance (in $\mathrm{cm}^{2}$ ) for the period 2000-2009 based on $5 \mathrm{~d}$ averages from (f) satellite altimetry data (AVISO) compared to the hindcast experiments in the different configurations: (a) ORCA05, (b) ORCA025 (based on monthly averages), (c) INALT10x, (d) INALT20 and (e) INALT10. The horizontal line in panel (e) at 50 $\mathrm{S}$ indicates the southern boundary of the nested region in INALT10; the boxes in panel (f) mark the areas used for time series analyses (see Fig. 5). Note: the discrepancy in the temporal resolution for ORCA025 does not alter the findings (not shown).

\subsection{Mesoscale variability}

The mesoscale is the dominating scale in the Agulhas region (Backeberg et al., 2008); its proper simulation is crucial for a reasonable representation of the dynamics in a numerical model. As a measure for mesoscale activity, SSH variance from satellite observations is compared to the modelled solutions (Fig. 3). Satellite altimetry data are provided by AVISO, interpolated to a $1 / 4^{\circ}$ Mercator grid with daily resolution. The daily data have been averaged into $5 \mathrm{~d}$ means prior to variance calculations over the 10-year long period (2000 to 2009) to allow for a direct comparison with the modelled SSH that is available at $5 \mathrm{~d}$ resolution except for the experiment in ORCA025 where only monthly averages are available.

From observations (Fig. 3f), several highly active regions can be identified: the Mozambique Channel and the eddy path from the southern branch of the East Madagascar Current towards the African coast, the meandering AC itself and, with the highest activity, the retroflection area and the Ag- ulhas Return Current. The path of Agulhas rings from the Indian into the Atlantic Ocean can be identified as elevated, although comparably weak, mesoscale activity. Aside from these regions, directly related to the $\mathrm{AC}$, three further areas of enhanced activity stand out: the Andrew Bain Fracture Zone (ABFZ) (Ansorge and Lutjeharms, 2005) south of Africa at approximately $50^{\circ} \mathrm{S} / 30^{\circ} \mathrm{E}$, the Malvinas Confluence Zone (MCZ) (Goni et al., 2011) on the other side of the Atlantic Ocean and a path of eddies entering the basin with the ACC.

In ORCA05, where the effect of eddies is parameterized, virtually no mesoscale activity is present (Fig. 3a). The eddy-permitting configuration ORCA025 (Fig. 3b; based on monthly averages) shows elevated levels of SSH variance in the most prominent regions of mesoscale activity, the retroflection area and along the Agulhas Return Current as well as in the MCZ but generally too weak. The AC and its upstream sources show no increased sign of mesoscale variability. However, in agreement with findings by Quartly et al. (2013), an accompanying experiment (not shown) with no slip along the lateral boundaries exhibits elevated mesoscale 


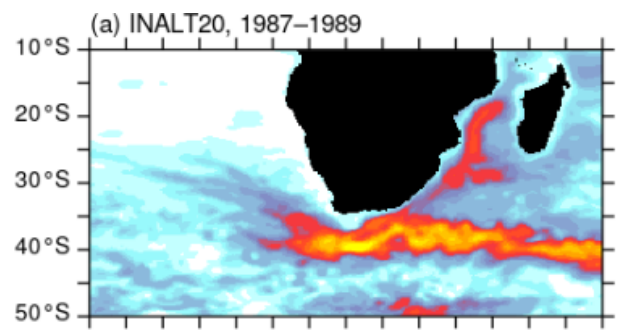

(c) INALT20, NS_RW, 2000-2009

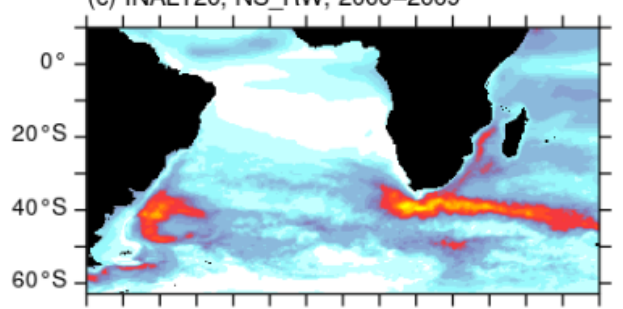

(e) INALT20, FS_AW, 2000-2009

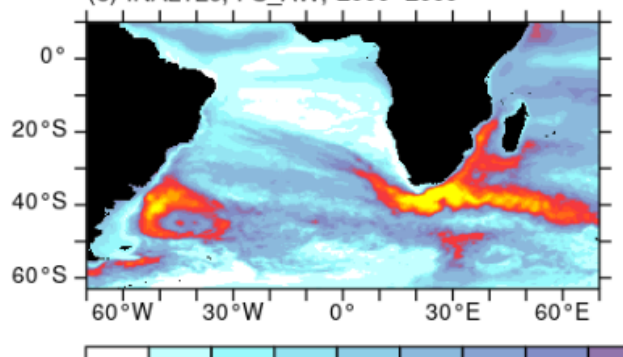

(b) INALT60, 1987-1989

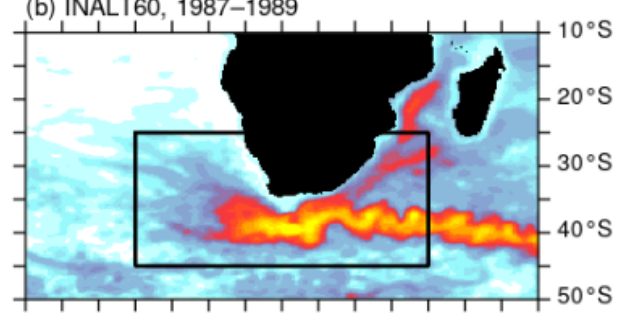

(d) INALT20, FS_RW, 2000-2009

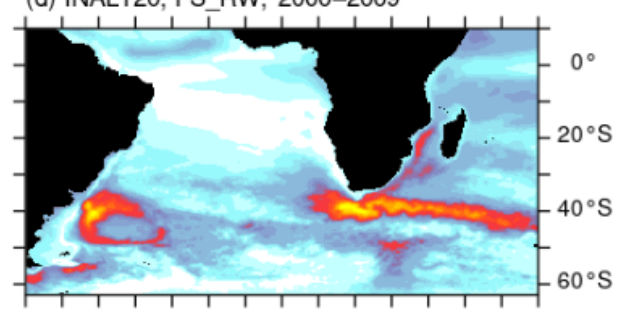

(f) INALT20, FS_PW, 2000-2009

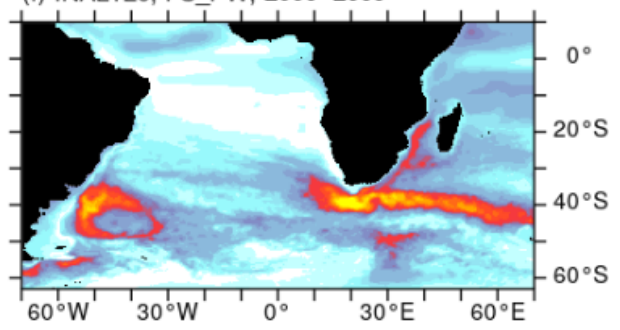

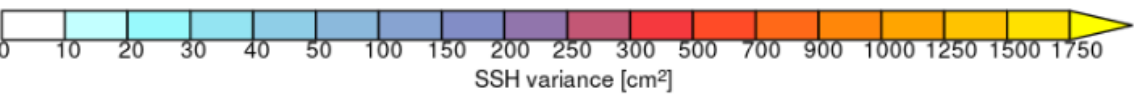

Figure 4. SSH variance (in $\mathrm{cm}^{2}$ ) for the period 1987 to 1989 from the spin-up experiments in (a) INALT20 and (b) INALT60 based on $5 \mathrm{~d}$ averages. The black box in panel (b) marks the region of the secondary $1 / 60^{\circ}$ nest in INALT60. Panels (c) to (f) give the SSH variance (in $\mathrm{cm}^{2}$ ) for the period 2000-2009 based on $5 \mathrm{~d}$ averages from the different sensitivity experiments in INALT20: (c) no slip, relative winds, (d) free slip, relative winds, (e) free slip, absolute winds, (f) free slip, partial winds.

variability here, due to the evolution of eddies in and propagation out of the Mozambique Channel. With increasing resolution, the representation of these large-scale features improves in strength and structure. INALT10(x) (Fig. 3c, e) and INALT20 (Fig. 3d) explicitly simulate variability in the source regions and in consequence a meandering and more variable AC.

The inflow of ACC eddies is adumbrated in ORCA025 but evolves to a distinct path only in INALT20 (Fig. 3d), where additionally the mesoscale activity in the MCZ becomes stronger and improved with respect to its spatial structure. The ABFZ as well as the Mozambique Channel and the area southwest of Madagascar begin to emerge as highly active regions, although still weaker compared to observations. INALT10x (Fig. 3c) also resolves mesoscale features, although weaker than in INALT20, in the specified areas, except for the ACC inflow that obviously evolves in a region located outside the nest in the non-eddying host grid. INALT10 (Fig. 3e), with its nested area limited to north of $50^{\circ} \mathrm{S}$, covers the variability around southern Africa and hence compares to INALT10x but lacks all mesoscale activity south of it. In consequence, it shows a different and weaker activity in the MCZ. All eddying simulations show a northwestward propagation of Agulhas rings into the Atlantic Ocean, while in the satellite observations, a rather zonal band between 30 and $40^{\circ} \mathrm{S}$ of elevated SSH variance marks their path.

In the greater AC system, mesoscale activity is comparable in INALT20 and INALT60 (Fig. 4a and b), with INALT20 showing a stronger variability in the Mozambique Channel and weaker levels in the retroflection area. INALT60 shows a slightly wider ring path into the Atlantic Ocean, although this can also be due to the short time span (3 years) used for the analysis.

Not only the resolution but also different parameterizations have an impact on the representation of the mesoscale variability as exhibited by sensitivity experiments in INALT20. Both the lateral boundary condition and the wind stress formulation have been modified. While changing the lateral boundary condition from no slip (Fig. 4c) to free slip (Fig. 4d) only slightly increases SSH variance southwest of Madagascar and in the ABFZ and reshapes the patch in the $\mathrm{MCZ}$, changing the wind formulation from relative to abso- 

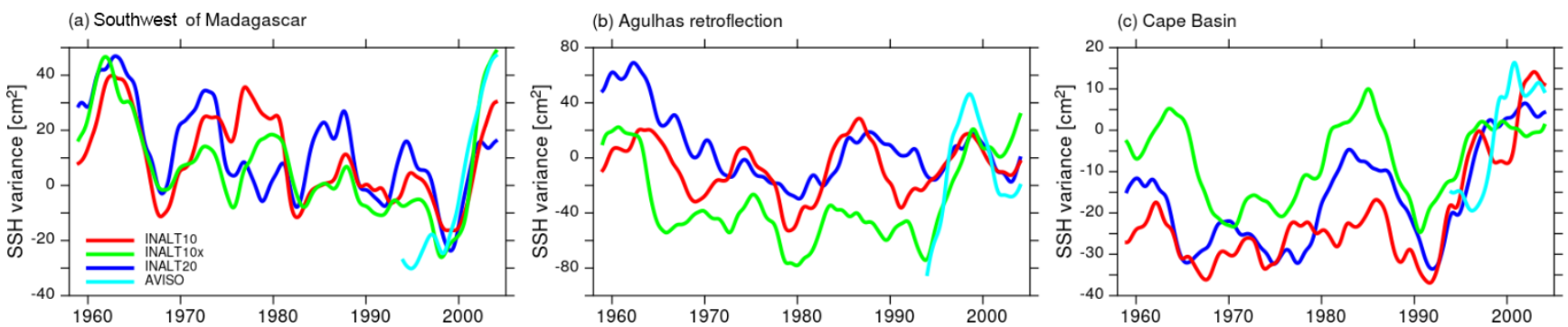

Figure 5. Time series of SSH variance anomalies to the 1995-2005 mean (in $\mathrm{cm}^{2}$ ) computed in a 5-year running window based on $5 \mathrm{~d}$ averages for the three different regions indicated in Fig. 3f from the nested configurations - INALT20 (blue) INALT10 (red) and INALT10x (green) - and from AVISO satellite altimetry (light blue). The curves are interannually filtered. For mean values and correlations, see Tables 4 and 5, respectively.

Table 4. Mean (2000-2009) SSH variance (in $\mathrm{cm}^{2}$ ) in the three different regions indicated in Fig. 3f: southwest of Madagascar (SOM), Agulhas retroflection (AR) and Cape Basin (CB). See Fig. 5 for corresponding anomaly time series.

\begin{tabular}{lccc}
\hline & SOM & AR & CB \\
\hline Observations & 331 & 794 & 160 \\
\hline INALT10 & 150 & 637 & 127 \\
INALT10x & 160 & 662 & 107 \\
INALT20 NS_RW & 183 & 654 & 127 \\
\hline INALT20 FS_RW & 180 & 765 & 131 \\
INALT20 FS_AW & 374 & 1197 & 248 \\
INALT20 FS_PW & 207 & 835 & 176 \\
\hline
\end{tabular}

lute winds (Fig. 4e) has a significant impact on the distribution of mesoscale variability. Although SSH variance is better represented in the Mozambique Channel and southwest of Madagascar as well as in the ABFZ and the MCZ in the simulation under absolute winds, the observed patterns south of Africa and along the Agulhas Return Current are overestimated in strength and extent resulting in unrealistically high variability. This also leads to a too-regular and too-pronounced path of Agulhas rings being shed into the Atlantic Ocean, a well-known behaviour (e.g. Biastoch et al., 2008c; Barnier et al., 2006) that is unacceptable for simulations being used to analyse $\mathrm{AC}$ and leakage influences on the Atlantic Ocean. An attempt to overcome the deficits of the two simulations under relative and absolute winds, respectively, is given by the partial wind experiment. It shows no significant improvement compared to the relative wind experiment (Fig. 4f), despite a slight elevation of variability in and south of the Mozambique Channel and in the MCZ. In consequence, we continue with the no-slip lateral boundary condition on the nest grid and relative winds for the reference experiment.

Time series of SSH variance, computed as the variance of $5 \mathrm{~d}$ data within a 5-year running window, provide a measure for the temporal variability in mesoscale activity. It is depicted for observations and the hindcast simulations in the nested configurations in Fig. 5 for three areas around South Africa: southwest of Madagascar (SOM), the Agulhas retroflection area (AR) south of Africa and the Cape Basin (CB) west of South Africa (boxes marked in Fig. 3f). It exhibits different types of variability. SSH variance southwest of Madagascar (Fig. 5a), dominated by variations originating in the Mozambique Channel, is marked by interannual variability with a period of approximately 7 years in all nested solutions. In this region, the SSH variance in INALT20 is on a slightly higher mean level than in the simulations at $1 / 10^{\circ}$ horizontal resolution but still strongly underestimates the observations (Table 4). The corresponding time series of SSH variance anomalies (Fig. 5) exhibit that the variability in the early period of the simulations is comparable among the different configurations, while in the subsequent decades, INALT10x stands out with reduced variations leading into a very strong increase towards the end of the simulation, in agreement with the observed anomalies, even exceeding the solution of INALT20. In this region, only INALT20 is significantly correlated with observations $(r=0.95$; see Table 5$)$ in the overlapping period (1995 to 2005), while the modelled solutions are all significantly correlated among themselves for the short period, mainly due to the decrease in the late 1990s followed by an increase in the 2000s.

In the Agulhas retroflection area (Fig. 5b), influenced by the AC and its meandering, the dominant period of variability is on decadal timescales in INALT10 and INALT10x and even longer in INALT20. The absolute values are comparable to, but still underestimating, the observations by $15 \%-20 \%$. Here, only INALT10 is significantly correlated with observations ( $r=0.90$; see Table 5). As southwest of Madagascar, all model simulations are significantly correlated in the observational period.

In the Cape Basin (Fig. 5c), the dominant variability is on decadal timescales in all simulations at comparable levels. In this region for the observational period, the variability on interannual timescales is uncorrelated, both between observations and the modelled solutions as well as between the different configurations. However, on longer timescales, 
Table 5. Correlations in SSH variance time series (yearly) (see Fig. 5) between AVISO and the nested configurations as well as among the nested configurations for the period 1995-2005 for the three regions indicated in Fig. 3f: southwest of Madagascar (SOM) | Agulhas retroflection (AR) | Cape Basin (CB). Significant correlations (at $95 \%$ confidence level) are given in bold.

\begin{tabular}{lccc}
\hline & INALT10 & INALT10x & INALT20 \\
\hline AVISO & $0.86|\mathbf{0 . 9 0}|-0.73$ & $0.84|0.87|-0.24$ & $\mathbf{0 . 9 5}|0.87| 0.32$ \\
INALT10 & & $\mathbf{0 . 9 9}|\mathbf{0 . 9 7}|-0.30$ & $\mathbf{0 . 8 8}|\mathbf{0 . 9 3}|-0.21$ \\
INALT10x & & & $\mathbf{0 . 8 8}|\mathbf{0 . 9 3}| 0.24$ \\
\hline
\end{tabular}

the correlations among the modelled solutions increase with INALT10x and INALT20 being significantly correlated at $95 \%$ confidence level (not shown). In contrast to the regions south of Madagascar and in the Agulhas retroflection area, the Cape Basin is located outside the most eddy-active region of the AC system within the path of the Agulhas rings that are shed into the Atlantic Ocean.

All configurations have a similar pattern of SSH variance for the three regions and all underestimate the mean, with INALT20 being closest to observations. The remarkable covariability on decadal timescales most probable stems from the common surface forcing. A detailed understanding of this is part of an individual research topic in itself and will be reconsidered elsewhere. In the greater Agulhas region, a horizontal resolution of $1 / 10^{\circ}$ locally appears to be enough to simulate mesoscale variability at a reasonable level, whereas the lack of mesoscale activity outside the nested region in INALT10 and INALT10x leads to an underestimation of mesoscale variability entering the South Atlantic through the Drake Passage and therefore in the MCZ and ABFZ. Among the configurations presented here, INALT20 simulates all the prominent mesoscale features within the region of interest most reasonably.

\subsubsection{Towards resolving the submesoscale - an outlook}

INALT60 with horizontal grid spacing below $2 \mathrm{~km}$ provides the necessary horizontal resolution to resolve scales down to $10 \mathrm{~km}$. In addition to the horizontal resolution, the vertical grid, the spatial and temporal resolution of the atmospheric forcing and the diffusion setup strongly control the simulation of the smaller-scale flows in the model. Developments to improve the configuration in the future are ongoing and are presented by Schubert et al. (2019). Here, a short outlook is given.

To adequately simulate the ocean currents potentially resolvable with the given horizontal grid, the vertical resolution needs at least to resolve the vertical structure of the corresponding horizontal flow which can be approximated by the baroclinic modes (Stewart et al., 2017). Based on hydrographic measurements, Stewart et al. (2017) provide a reference for the required vertical resolution to resolve the first, second and third baroclinic modes. A new vertical grid, that shall resolve the third baroclinic mode, with 120 vertical levels and a grid spacing of $1 \mathrm{~m}$ near the surface, $10 \mathrm{~m}$ at about
$350 \mathrm{~m}$ depth and $100 \mathrm{~m}$ in the deep ocean is under development. A very high vertical resolution is required in the mixed layer, as submesoscale currents mainly occur in boundary layers and are surface intensified (McWilliams, 2016). The mixed layer depth in the midlatitude regions of the storm tracks, such as the Agulhas region, is associated with a strong seasonal cycle. Weaker wind stress in summer leads to a thin mixed layer of down to less than $20 \mathrm{~m}$, while stronger wind stress in winter leads to a thick mixed layer exceeding $150 \mathrm{~m}$ (de Boyer Montégut et al., 2004). To resolve smaller-scale flows within the mixed layer also during summertime, at least 10 vertical levels in the uppermost $20 \mathrm{~m}$ are required.

Near-surface submesoscale features, resolvable with a $1 / 60^{\circ}$ configuration, evolve at timescales of less than a day (McWilliams, 2016). Due to the subdaily timescales, a realistic representation of the daily cycle in the forcing fields is necessary for simulating the submesoscales properly. The CORE atmospheric forcing is given at relatively coarse resolution in space $\left(2^{\circ} \times 2^{\circ}\right)$ and time (6-hourly for the highest resolved fields). For simulations with INALT60, the higher resolved JRA55-do forcing (Tsujino et al., 2018), which is associated with relatively higher horizontal $\left(0.5^{\circ} \times 0.5^{\circ}\right)$ and temporal (3-hourly) resolutions, will be used in the future.

Both the numerical diffusion associated with advection schemes for tracer and momentum and the explicit diffusion in the primitive equations contribute to the model diffusion. So far, the same model diffusion setup is used for INALT60 and INALT20: TVD scheme and Laplacian explicit diffusion with constant diffusion coefficient for tracers and vector-invariant advection scheme with EEN vorticity formulation supported by bi-Laplacian explicit viscosity with a constant viscosity coefficient for momentum. The diffusion coefficient has been linearly (quadratically) scaled down with the grid spacing for tracers (momentum). The coefficient thereby has to be large enough to prevent the strongest simulated shears from numerical instability. A disadvantage of this method is that moderate shears that would not have led to numerical instability are also damped. In the future, a thirdorder upstream-biased scheme (UBS; Webb et al., 1998; Farrow and Stevens, 1995; Madec and the NEMO team, 2014) for tracer and momentum will be used. This scheme is numerically diffusive enough to inhibit numerical instabilities at the grid scale. Explicit diffusion with UBS is only needed if the numerical diffusion is not large enough to be realis- 


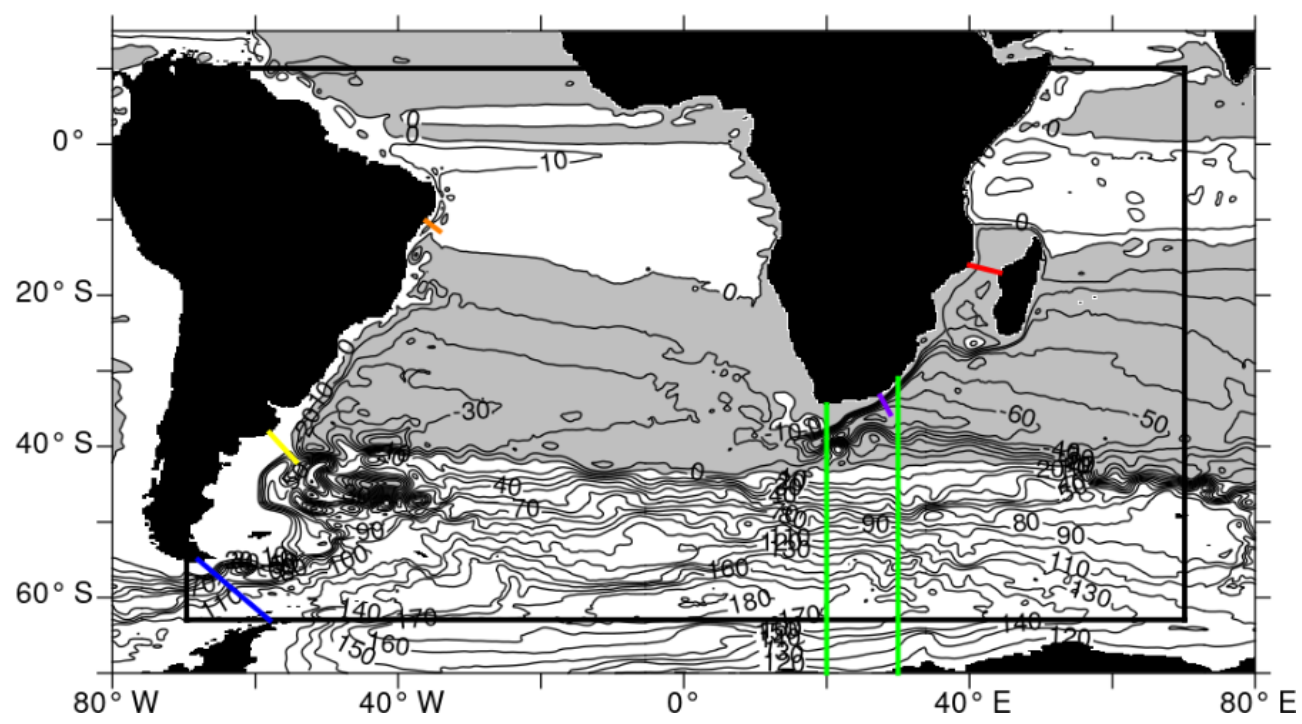

Figure 6. Mean (2000-2009) barotropic stream function as simulated within INALT20 (nested region demarcated by the black box). Grey shading indicates anti-cyclonic circulation; contours are in $10 \mathrm{~Sv}$ intervals. The band for ACC transport calculations south of Africa is marked by the green lines; the Drake Passage is indicated in blue; the location of the LOCO array is given in red, the section crossing the Malvinas Current in yellow and the section crossing the North Brazil Current in orange. The purple line indicates the location of the ACT array that is referred to in Sect. 3.4.

tic. The evaluation of the model performance with UBS and a respective validation against observations is presented by Schubert et al. (2019).

\subsection{Horizontal gyre circulation and transport}

An important consequence of the open setting of the AC system is the connection between the subtropical gyres in the Indian and Atlantic oceans. This connection south of Africa represented by the Agulhas leakage (see Sect. 3.5) is part of the Southern Hemisphere "supergyre" (Speich et al., 2007). Only a certain portion of the water arriving in the South Atlantic through the AC system becomes part of the AMOC. According to models, about $40 \%-50 \%$ recirculate in the horizontal gyre circulation in the South Atlantic at least once (Rühs et al., 2013, 2019).

All model configurations share the same structure and extent of the supergyre (Fig. 6, only INALT20 is shown exemplarily), which is, to first order, a consequence of the surface forcing fields. The horizontal streamfunction conveniently provides measures of transport across individual sections. Below, we evaluate transport of the ACC and through the Mozambique Channel.

Furthermore, the Malvinas Current (MC) and the North Brazil Current (NBC), two important western boundary currents in the South Atlantic, provide a measure for transport in the subtropical gyre in the South Atlantic and the interhemispheric transport from the south towards the North Atlantic (Rühs et al., 2015). The MC has been suggested to play a significant role for the upper limb of the Atlantic meridional overturning (Fricourt et al., 2005): north of the pre- sented section, the MC collides with the southward Brazil Current forming the Brazil-Malvinas Confluence Zone, one of the regions in the world's oceans with highest eddy activity (see analyses of SSH variance in Sect. 3.1). The current is suggested to then transport water across the Atlantic Ocean towards the east, entering the South Atlantic Current and, further downstream, the NBC which transports the water across the Equator (Hummels et al., 2015).

\subsubsection{Transport of the ACC}

The mean ACC transport south of Africa, estimated by the maximum in the barotropic stream function between 20 and $30^{\circ} \mathrm{E}$, following Durgadoo et al. (2013), is 175 and $178 \mathrm{~Sv}$ in the non-eddying configurations (ORCA05 and INALT10), respectively, and $20 \mathrm{~Sv}$ stronger if eddies are (at least partially) resolved in ORCA025, INALT10x and INALT20 (Fig. 7a). Evans et al. (2017) review a series of observational estimates of the ACC transport across $30^{\circ} \mathrm{E}$ resulting in a range between 131.7 and 160 Sv. However, the difference in the transport from the simulations here is mainly due to a recirculation gyre in the Weddell Sea, rather than to the different strength of the ACC (Fig. 6). The transport through the Drake Passage shows a different picture (Fig. 7b). In INALT10x and INALT20, the Drake Passage is located directly at the margin of the nested area, whereas in INALT10, whose southern boundary is located at $50^{\circ} \mathrm{S}$, it is outside of the nest. The simulated mean transport is weaker $(\sim 117 \mathrm{~Sv})$ within the configurations with an eddying representation of the Drake Passage (ORCA025 and INALT20) than with a non-eddying representation (ORCA05 

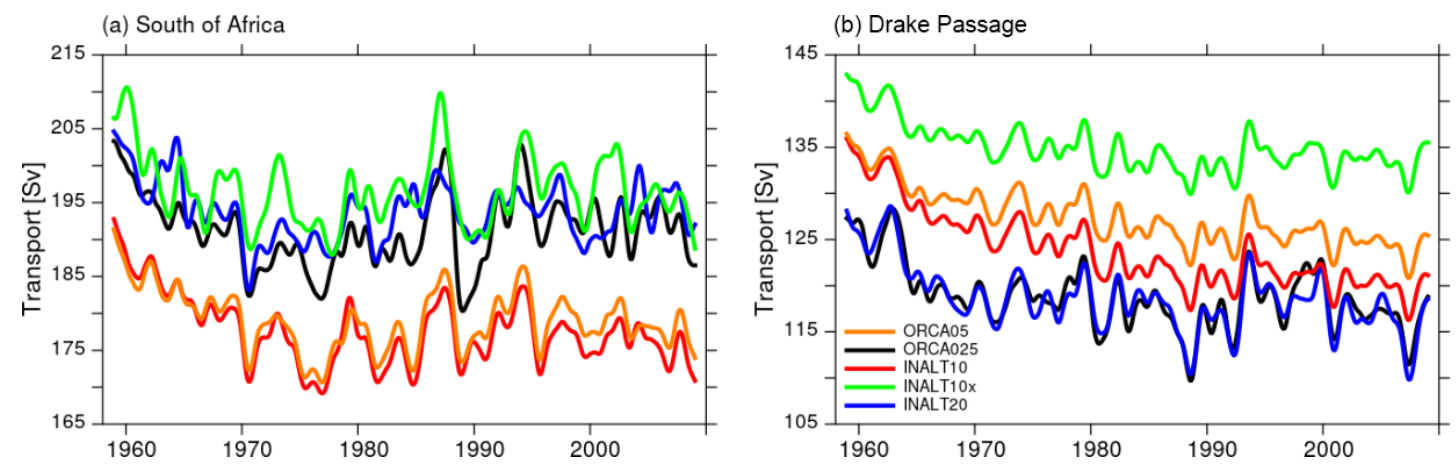

Figure 7. Time series of ACC transport (in Sv) as given by the maximum in the barotropic stream function south of Africa between 20 and $30^{\circ} \mathrm{E}$ (a) and the barotropic transport through the Drake Passage (b) for ORCA025 (black), INALT20 (blue), ORCA05 (orange), INALT10 (red) and INALT10x (green).

(a) Absolute transport

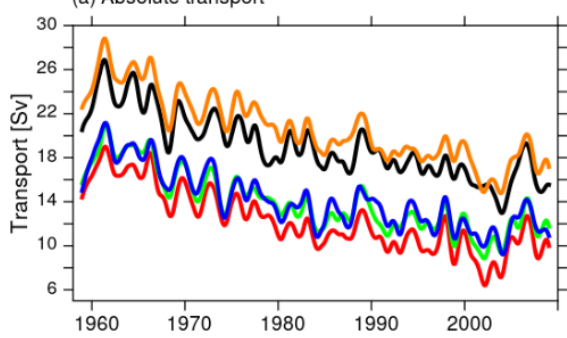

(b) Anomalies

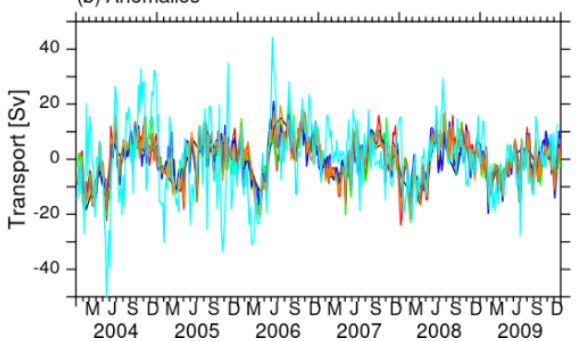

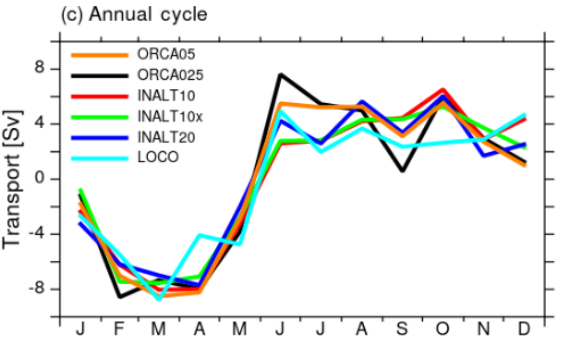

Figure 8. Time series of the southward barotropic transport through the Mozambique Channel (in Sv) as absolute values (a) and anomalies (b) compared to observations. The seasonal cycle of the anomalies for the period 2004 to 2009 is given in panel (c).

and INALT10; 122 Sv). The latter two configurations however separate over time, with INALT10 being subject to a stronger decline of the ACC. In contrast to INALT10, INALT10x shows a higher transport ( $133 \mathrm{~Sv})$, due to a larger geostrophic component across the ACC. Given the current uncertainty in observational values for the Drake Passage transport ranging from $124.7 \pm 9.9 \mathrm{~Sv}$ (Whitworth and Peterson, 1985) via $136.7 \pm 7.8 \mathrm{~Sv}$ (Cunningham et al., 2003) to $173.3 \pm 10.7 \mathrm{~Sv}$ (Donohue et al., 2016), it is difficult to identify the more realistic configurations; however, the estimates from all configurations are at the lower end. On interannual timescales, the simulated transport time series are significantly correlated among all the configurations with highest values $>0.97$ between ORCA05 and INALT10(x), 0.91 between ORCA025 and INALT20, and 0.89 between INALT10x and INALT20. The reduction in correlation values is due to non-linearities, decoupling the individual transport from the common wind forcing.

\subsubsection{Transport through the Mozambique Channel}

All simulations exhibit the same interannual variability and declining trend of the barotropic transport through the Mozambique Channel but with different long-term mean states. Although all runs experience a similar long-term decline of $1.5 \mathrm{~Sv}$ per decade, it is to note that an accompany- ing ORCA025 experiment with repeated-year forcing is not subject to a significant trend (not shown). Consequently, this trend is rather not an effect of model drift but likely to be related to trends in wind stress and wind stress curl over the Indian Ocean (DiMarco et al., 2002).

At $\sim 17^{\circ} \mathrm{S}$, a mooring array of the Long-term Ocean Climate Observations (LOCO) Indian Ocean programme has been established in 2003 (Ridderinkhof et al., 2010), providing an observational time series of the net transport through the Mozambique Channel. The comparison between these observed and the simulated transport anomaly time series of the different configurations exhibits a strong correspondence on seasonal to interannual timescales (Fig. 8b). Before mid-2006, when a transition from a phase that is marked by high variability to a phase with less fluctuations in the Mozambique Channel transport (van der Werf et al., 2010; Ullgren et al., 2012), the higher-frequency fluctuations are underestimated by all model configurations. After this transition in 2006, all simulations capture the variability quite well, except for some observed extrema like in July 2008 or June 2009. The mean values, however, are underestimated in the high-resolution configurations with only $10.0 \mathrm{~Sv}$ (INALT10) and 11.6 Sv (INALT10x and INALT20) compared to the observed 16.4 Sv (Table 6). The un-nested models do better in representing this mean transport with $16.1 \mathrm{~Sv}$ in ORCA025 and an overestimating $17.4 \mathrm{~Sv}$ in ORCA05. While 
Table 6. Mean (2004-2009) transport (in Sv) through the Mozambique Channel (MOZ) and correlations between observed and modelled transport time series based on monthly averages including|subtracting the seasonal cycle. Correlations, significant at $95 \%$ confidence level, are given in bold.

\begin{tabular}{lll}
\hline & MOZ & Correlations \\
\hline Observations & 16.5 & \\
\hline ORCA05 & 17.4 & $\mathbf{0 . 6 2} \mid \mathbf{0 . 5 3}$ \\
ORCA025 & 16.1 & $\mathbf{0 . 5 3} \mid 0.36$ \\
INALT10 & 10.0 & $\mathbf{0 . 6 1} \mid \mathbf{0 . 4 7}$ \\
INALT10x & 11.6 & $\mathbf{0 . 6 2} \mid \mathbf{0 . 5 0}$ \\
INALT20 NS_RW & 11.6 & $\mathbf{0 . 6 2} \mid \mathbf{0 . 5 1}$ \\
\hline INALT20 FS_RW & 14.4 & $\mathbf{0 . 4 9} \mid 0.23$ \\
INALT20 FS_AW & 15.5 & $\mathbf{0 . 6 1} \mid 0.45$ \\
INALT20 FS_PW & 15.3 & $\mathbf{0 . 6 3} \mid \mathbf{0 . 5 2}$ \\
\hline
\end{tabular}

in the non-eddying configurations this is an effect of the freeslip solution and the unrealistic current in the Mozambique Channel, the underestimation in the eddying configurations points to a still under-represented transport in the Mozambique eddies (van der Werf et al., 2010).

In the sensitivity experiments with INALT20, free-slip lateral boundary conditions cause an increase in mean transport by about $50 \%$ (Table 6), while the variability remains comparable.

The seasonal cycle of the Mozambique Channel transport (Fig. 8c) is very robust among the different simulations and is in agreement with observations. van der Werf et al. (2010) ascribe the seasonal cycle to yearly variations in the wind forcing west of $75^{\circ} \mathrm{E}$. It is interesting to note that a major part of the good correlation between the simulated and observed values is due to the realistic representation of this seasonal cycle (Table 6).

\subsubsection{Malvinas Current}

The MC originates in the Drake Passage as the northern branch of the ACC, turning northward along the South American continental slope into the Atlantic Ocean. It consists of multiple jets (Piola et al., 2013) that align towards the north into a coherent current at $41^{\circ} \mathrm{S}$ whose mean structure and temporal variability have been assessed based on mooring data and satellite altimetry (Artana et al., 2018). Here, a comparison with the mean structure of the Malvinas Current as simulated in the different configurations is given (Fig. 9). ORCA05 and INALT10 both lack a MC at $41^{\circ} \mathrm{S}$, due to a recirculation towards the east located further south that can be attributed to the missing resolution in the ACC and a consequently weaker $\mathrm{MC}$. The configurations covering the entrance of the ACC into the Atlantic basin at eddying resolution (ORCA025, INALT10x and INALT20) all show a wide band of northward surface-intensified velocities with a core
Table 7. Mean (2000-2009) transport (in Sv) of the Malvinas Current (MC) at $41^{\circ} \mathrm{S}$ and the North Brazil Current (NBC) at $11^{\circ} \mathrm{S}$. Observational values are from Artana et al. (2018) and Hummels et al. (2015), respectively.

\begin{tabular}{lcc}
\hline & MC & NBC \\
\hline Observations & $37.1 \pm 2.6$ & $23 \pm 3$ \\
\hline ORCA05 & 10.3 & 13.7 \\
ORCA025 & 25.1 & 17.7 \\
INALT10 & 16.7 & 19.3 \\
INALT10x & 32.5 & 18.8 \\
INALT20 NS_RW & 37.2 & 20.5 \\
\hline INALT20 FS_RW & 48.5 & 18.8 \\
INALT20 FS_AW & 47.8 & 19.4 \\
INALT20 FS_PW & 47.4 & 18.3 \\
\hline
\end{tabular}

located between 70 and $80 \mathrm{~km}$ off-coast. The mean transport increases with increasing resolution from $25 \mathrm{~Sv}$ in ORCA025 to $37 \mathrm{~Sv}$ in INALT20 (see Table 7 for all mean transport values). The latter well fits the observed transport, although it features weaker velocities over a wider current core than in observations (Artana et al., 2018, their Fig. 5a).

The sensitivity experiments in INALT20 show, due to the free-slip condition, a current core that is located closer to the coast, with a structure that better resembles the observed (Fig. 9f) but with overestimated velocities leading to a mean transport value of roughly $48 \mathrm{~Sv}$ independent from the applied wind stress formulation (Table 7).

\subsubsection{North Brazil Current}

The NBC forms a bottleneck for water from the South Atlantic on its way into the North Atlantic and is therefore crucial for the interhemispheric exchange and the AMOC (Rühs et al., 2015; Hummels et al., 2015). The representation of the NBC in the different model configurations is evaluated by comparing the current structure and mean transport with observations at $11^{\circ} \mathrm{S}$ (Fig. 10). The observed NBC shows a subsurface core, wherefore it is also referred to as North Brazil Undercurrent, located at $35.7^{\circ} \mathrm{W}$ off the coast of Brazil. The current reaches off-coast to approximately $35.2^{\circ} \mathrm{W}$ and down to $1200 \mathrm{~m}$ with core velocities of roughly $0.5 \mathrm{~m} \mathrm{~s}^{-1}$ (Hummels et al., 2015, their Fig. 1b). The mean NBC transport is evaluated to $23 \pm 3 \mathrm{~Sv}$. The NBC in ORCA05 is located further off-shore, with underestimated velocities leading to a mean transport of only $13.7 \mathrm{~Sv}$. With increasing resolution, the mean transport also increases up to $20.5 \mathrm{~Sv}$ in INALT20 (see Table 7 for all transport values). The current structure also improves with increasing resolution, with the current core moving towards the coast and the observed tilted shape becoming more pronounced.

The NBC in the sensitivity experiments in INALT20 is of slightly weaker strength when compared to the reference ex- 
(a) ORCA05

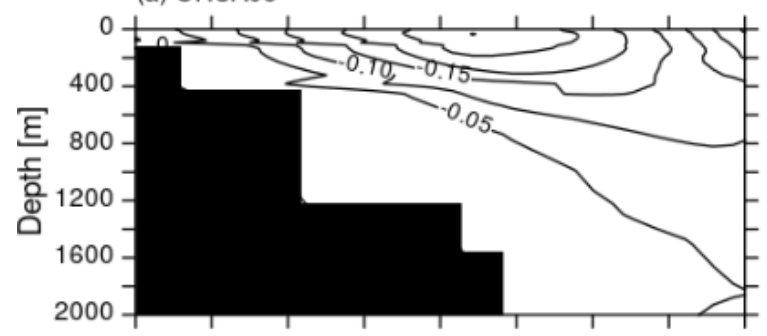

(c) INALT10x

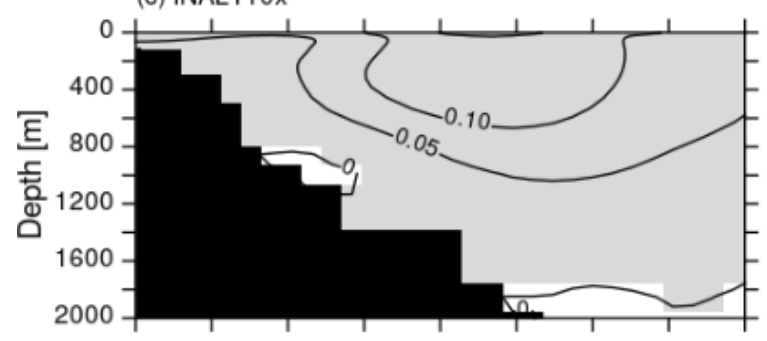

(e) INALT10

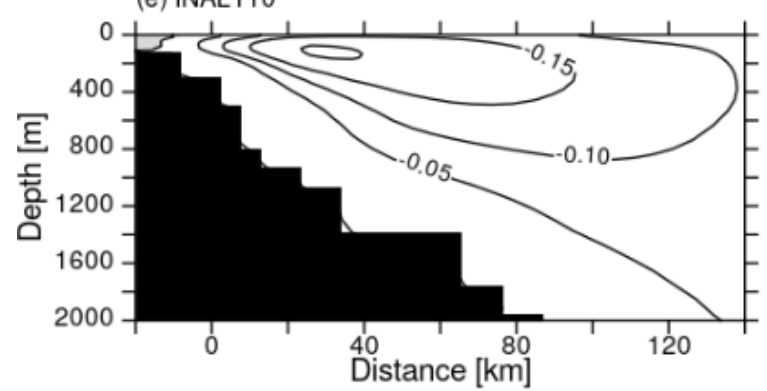

(b) ORCA025

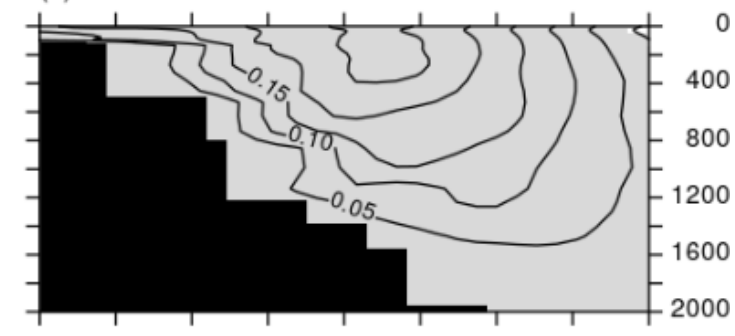

(d) INALT20, no slip

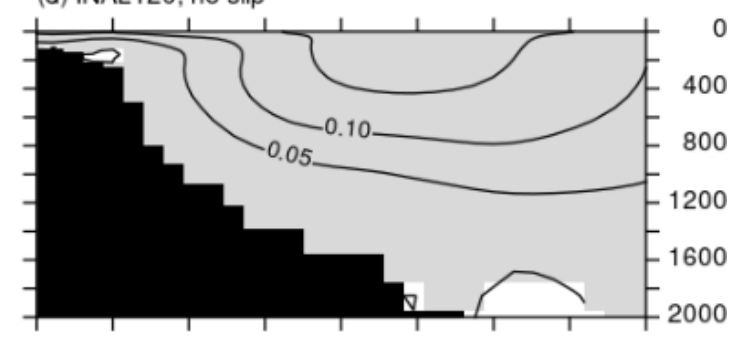

(f) INALT20, free slip

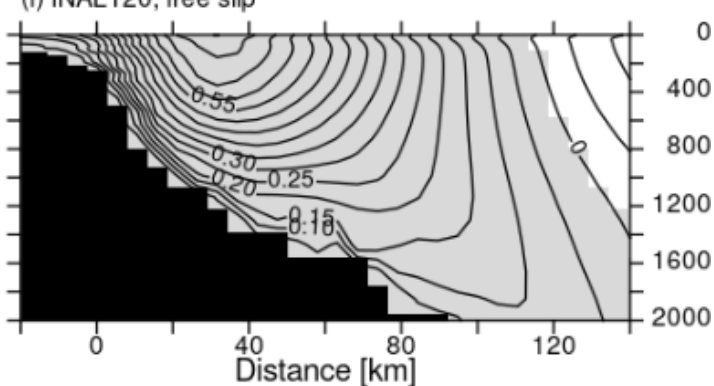

Figure 9. Mean (2000-2009) MC structure at $41^{\circ} \mathrm{S}$ from ORCA05 (a), ORCA025 (b), INALT10x (c), INALT20 NS_RW (d), INALT10 (e) and INALT20 FS_RW (f). Note that southwestward/negative velocities are shaded in white and northeastward/positive in grey; contoured are intervals of $5 \mathrm{~cm} \mathrm{~s}^{-1}$.

periment (Table 7) with a more coastally confined current structure due to the free-slip condition (Fig. 10f). As for the $\mathrm{MC}$, the wind stress formulation is of minor importance for the representation of the NBC.

The strengths of the western boundary currents in the South Atlantic are represented reasonably well in INALT20, while the configurations that have a coarser resolution at these locations underestimate the mean current transport. The sensitivity experiments in INALT20 exhibit a strong dependency of the MC structure and strength on the lateral boundary condition, while the NBC is comparably robust.

\subsection{Atlantic meridional overturning circulation}

Due to the interoceanic exchange south of Africa, the AC system plays a role in the global overturning circulation (Gordon, 1986). Here, surface and intermediate waters are transported from the Indian Ocean into the Atlantic (Biastoch and Böning, 2013) and eventually become part of the AMOC (Rühs et al., 2013; Biastoch et al., 2009b). On decadal timescales, AMOC anomalies with origin in the AC system are reflected in the AMOC in the South and North Atlantic (Biastoch et al., 2008a). On multi-decadal timescales, Agulhas leakage impacts the Atlantic hydrography and heat content (Biastoch et al., 2015; Lübbecke et al., 2015). A proper representation of the AMOC is therefore crucial to study not only the embedment of the AC system within the global circulation but also the feedback on the North Atlantic.

The simulated mean structure of the zonally integrated meridional velocities is similar among all simulations (Fig. 11), representing the expected structure: an upper cell with northward transport above $\sim 1000 \mathrm{~m}$ depth, sinking north of $\sim 40^{\circ} \mathrm{N}$, and southward flow from $\sim 1000 \mathrm{~m}$ depth down to $\sim 3500 \mathrm{~m}$ depth, transporting North Atlantic Deep Water - the North Atlantic Deep Water cell. Underneath, Antarctic Bottom Water (AABW) invades the Atlantic basin from the south, forming the deep AABW cell with northward transport below $\sim 4000 \mathrm{~m}$ depth. Both cells increase in strength with increasing horizontal resolution of the model configurations. 
(a) ORCA05

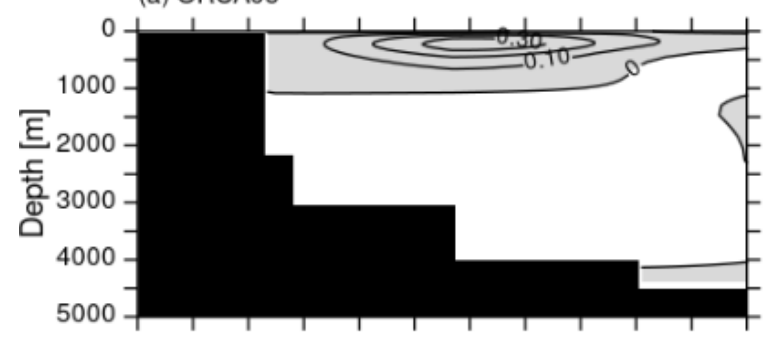

(c) INALT10x

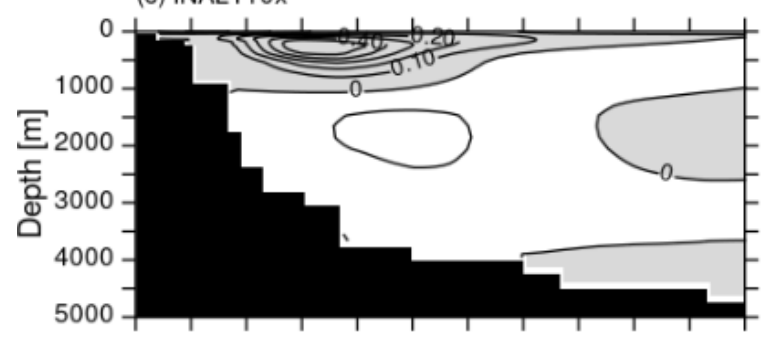

(e) INALT10

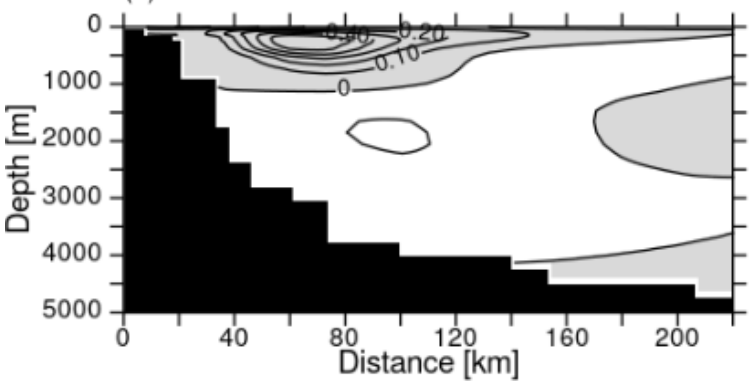

(b) ORCA025

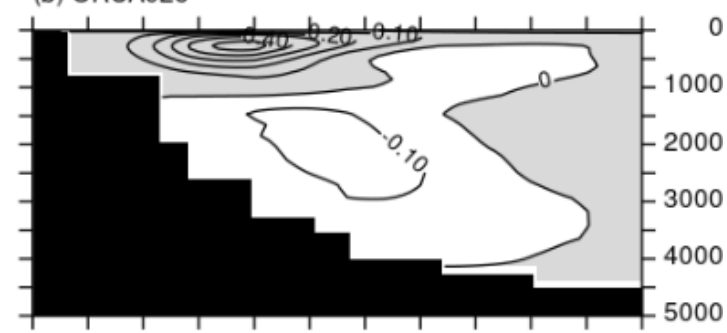

(d) INALT20, no slip

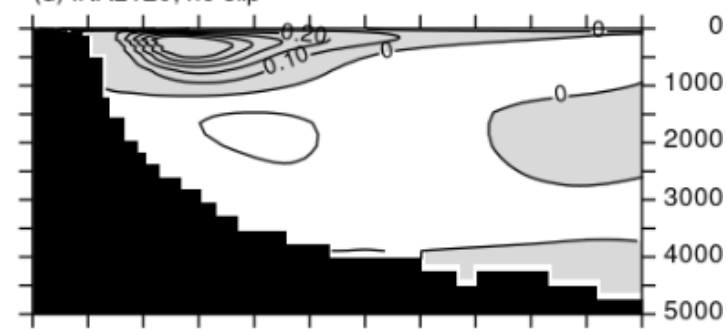

(f) INALT20, free slip

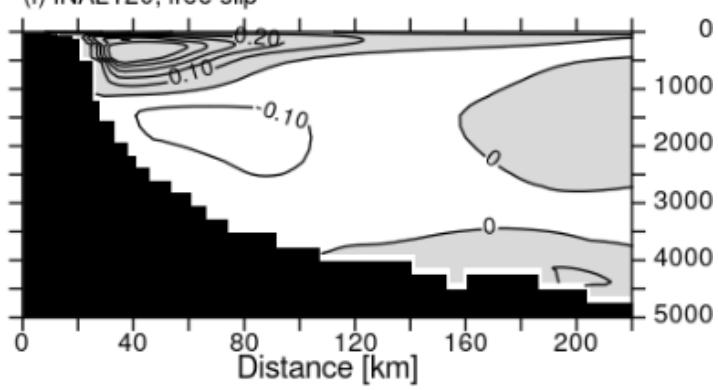

Figure 10. Mean (2000-2009) NBC structure at $11^{\circ} \mathrm{S}$ from ORCA05 (a), ORCA025 (b), INALT10x (c), INALT20 NS_RW (d), INALT10 (e) and INALT20 FS_RW (f). Note that southwestward/negative velocities are shaded in white and northeastward/positive in grey; contoured are intervals of $10 \mathrm{~cm} \mathrm{~s}^{-1}$.

With increased horizontal grid resolution on the global scale, from ORCA05 to ORCA025, and also from the host to the respective nests, from ORCA05 to INALT10x and from ORCA025 to INALT20, the strength of the upper and lower overturning cells increases. For INALT10, this relationship holds only for the upper overturning cell, while the AABW cell is slightly weaker represented than within ORCA05. Due to the reduced southward extend of the high-resolution nest in INALT10 this can be attributed to the missing effect of resolved transport of AABW across the subtropical front. The same argument accounts for the strengthening of the lower overturning cell comparing INALT10x and INALT20, implying the need for resolutions beyond $1 / 10^{\circ}$ to represent the impact of the mesoscale on deep water formation in the Southern Ocean. Changing the lateral boundary condition in INALT20 from no slip to free slip shows a strengthening of the deep AABW cell. Consequently, the stronger AABW cell slightly lifts and, more importantly, dampens the upper overturning cell as suggested by Frajka-Williams et al. (2011) from hydrographic observations at $24.5^{\circ} \mathrm{N}$ as well as from modelling studies (e.g. Swingedouw et al., 2009; Martin et al., 2015).

The model simulations all underestimate the observed AMOC transport. In the South Atlantic, located at $34.5^{\circ} \mathrm{S}$ (Ansorge et al., 2014), the South Atlantic MOC basinwide array (SAMBA, embedded in the South Atlantic MOC (SAMOC) initiative; Garzoli et al., 2013) started to continuously monitor the meridional overturning circulation in 2002. Meinen et al. (2018) evaluate their measurements to a transport of $14.7 \mathrm{~Sv}$, highly energetic and with strong variations on various timescales. The modelled transport ranges between 11.1 and $13.8 \mathrm{~Sv}$, showing a strengthening with increasing model resolution (Table 8). At $26.5^{\circ} \mathrm{N}$, where observational measurements derived from RAPID (Rayner et al., 2011; Smeed et al., 2017) provide a reference value for the maximum overturning transport of $17.7 \mathrm{~Sv}$ for the period 2005 to 2009; the simulated transport is 3 to $4.5 \mathrm{~Sv}$ weaker, which is a typical behaviour of models with limited horizontal resolution in the North Atlantic not being able to correctly resolve the mesoscale and consequently the correct characteristic and spreading of lower North Atlantic Deep Water from its for- 
(a) ORCA05

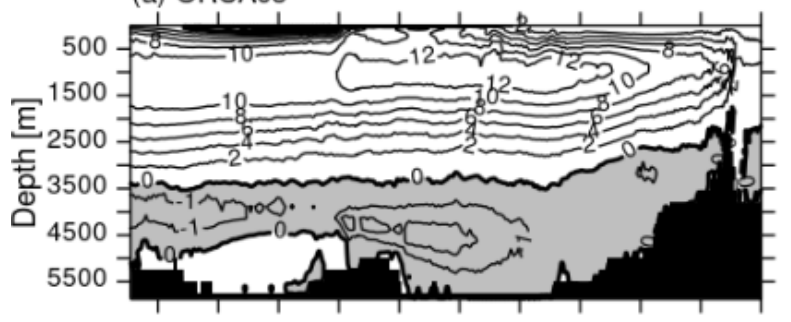

(c) INALT10x

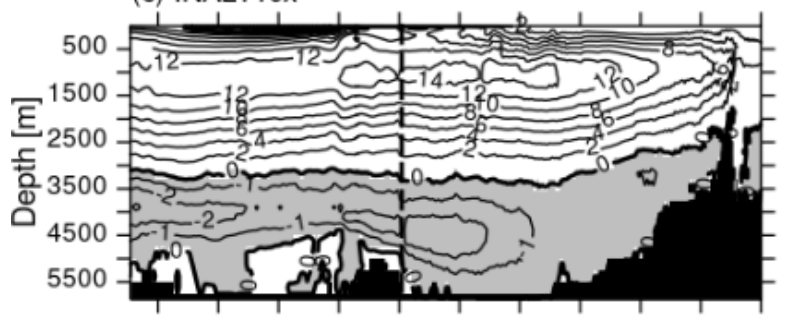

(e) INALT10

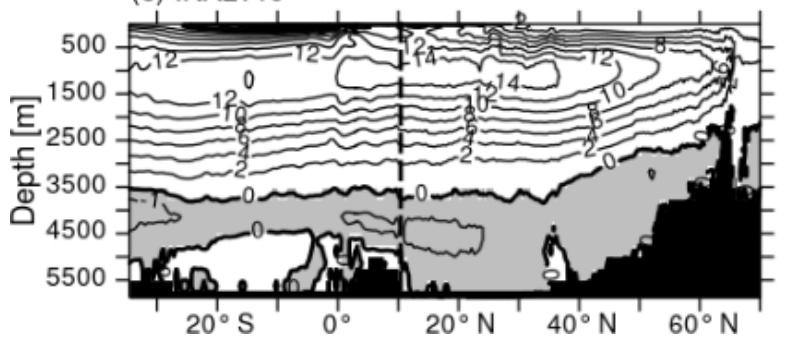

(b) ORCA025

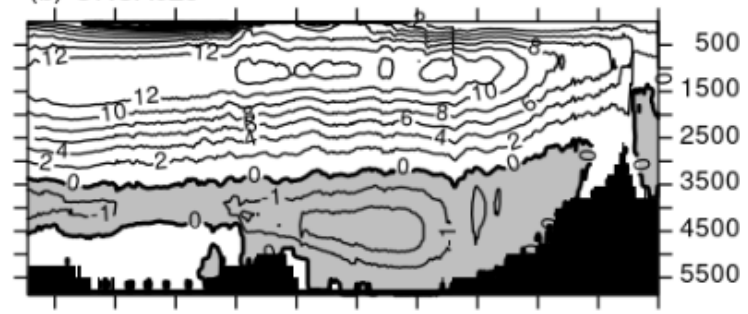

(d) INALT20, no slip

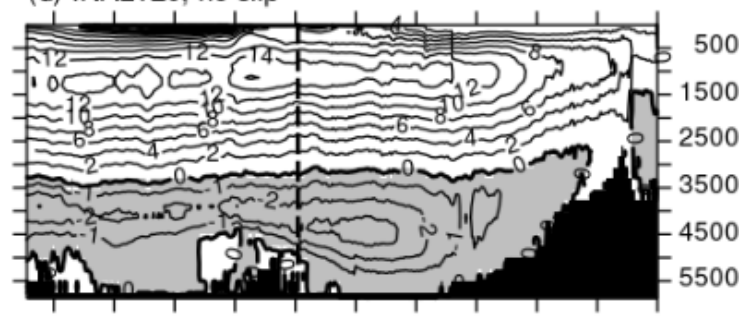

(f) INALT20, free slip

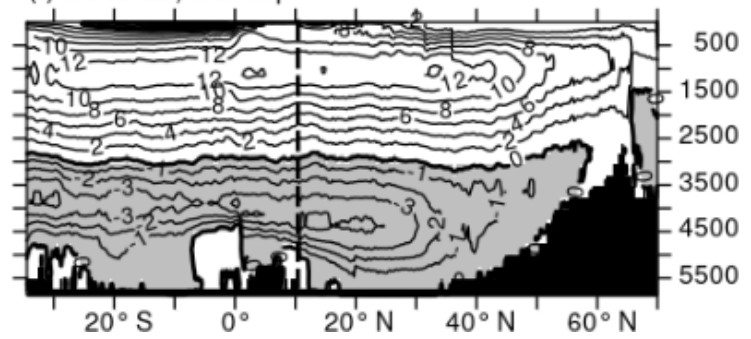

Figure 11. Mean AMOC (in Sv) for the period 2005-2009 from the hindcast experiments within the different configurations: (a) ORCA05, (b) ORCA025, (c) INALT10x, INALT20 with no-slip (d) and free-slip (f) lateral boundary condition and (e) INALT10. The dashed lines in panels (c) to (f) indicate the northern boundary of the nested regions. Contour intervals are $1 \mathrm{~Sv}$ for negative (grey shaded) and $2 \mathrm{~Sv}$ for positive (white) transport.

(a) $34.5^{\circ} \mathrm{S}$

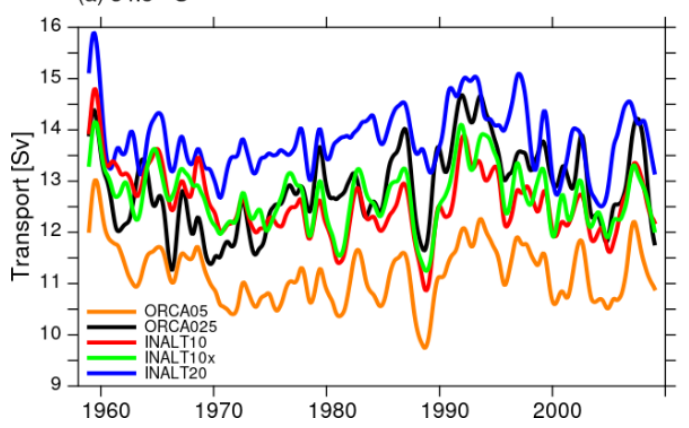

(b) $26.5^{\circ} \mathrm{N}$

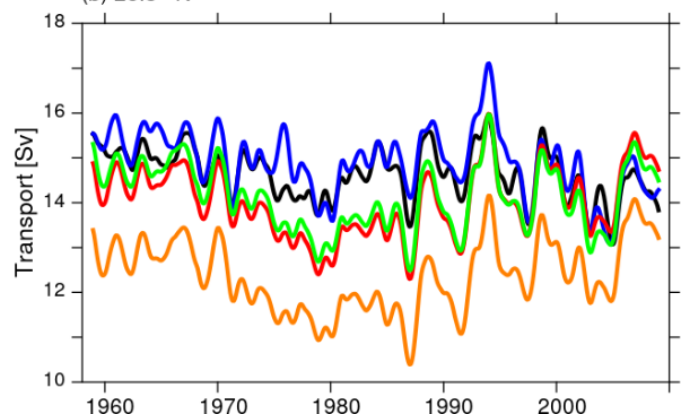

Figure 12. Time series of AMOC transport (in Sv) at $34.5^{\circ} \mathrm{S}$ (a) and $26.5^{\circ} \mathrm{N}$ (b) from ORCA025 (black), INALT20 (blue), ORCA05 (orange), INALT10 (red) and INALT10x (green)

mation region in the Nordic Seas through the Denmark Strait into the subpolar North Atlantic (Behrens et al., 2013, 2017; Böning et al., 2016).

The temporal evolution of the AMOC strength (Fig. 12) shows an admittedly weak but stable AMOC with long-term trends all well below $\pm 1 \mathrm{~Sv}$ per decade. In the North Atlantic, at $26.5^{\circ} \mathrm{N}$, interannual correlations are above 0.86 among the simulations in the different configurations, while in the south, at $34.5^{\circ} \mathrm{S}$, the correlations are between 0.4 and 0.7 except for ORCA05 and INALT10 with a correlation of 0.8 (see Table 9 for all correlation coefficients). The high correlations in the north are an expression for the determination of the interannual variability by the applied forcing, which is the same for all simulations. Here, none of 
Table 8. MOC transport at $34.5^{\circ} \mathrm{S} \mid 26.5^{\circ} \mathrm{N}$ (in Sv) averaged over the full integration period (1958 to 2009) and the respective standard deviations (SDs) on interannual timescales and for the period 2005-2009 compared to observations from Meinen et al. (2018) for $34.5^{\circ} \mathrm{S}$ and RAPID at $26.5^{\circ} \mathrm{N}$ (http://www.rapid.ac.uk/rapidmoc, last access: 24 January 2018), respectively.

\begin{tabular}{lcc}
\hline & $1958-2009($ mean \pm SD $)$ & 2005-2009 \\
\hline Observations & & $14.7 \mid 17.7$ \\
\hline ORCA05 & $11.2 \pm 0.56 \mid 12.4 \pm 0.79$ & $11.1 \mid 13.2$ \\
ORCA025 & $12.9 \pm 0.79 \mid 14.6 \pm 0.56$ & $12.8 \mid 13.9$ \\
INALT10 & $12.6 \pm 0.63 \mid 14.0 \pm 0.76$ & $12.4 \mid 14.7$ \\
INALT10x & $12.7 \pm 0.57 \mid 14.1 \pm 0.73$ & $12.4 \mid 14.5$ \\
INALT20 NS_RW & $13.8 \pm 0.61 \mid 14.9 \pm 0.70$ & $13.8 \mid 14.2$ \\
\hline INALT20 FS_RW & & $12.2 \mid 13.3$ \\
INALT20 FS_AW & & $12.1 \mid 13.5$ \\
INALT20 FS_PW & & $12.2 \mid 13.3$ \\
\hline
\end{tabular}

the nested configurations are represented at eddying resolution. Consequently, the particular nested configurations show a good correlation with the corresponding un-nested configurations with the same horizontal resolution (INALT10(x) and ORCA05 as well as INALT20 and ORCA025). In the south, the correlations among the model solutions are reduced due to the partly resolved mesoscale and the associated non-linearities. This is highlighted by the difference in comparing INALT10 to ORCA05 and INALT20 to ORCA025. The nearly fully resolved mesoscale in INALT20 effectively reduces the correlation (although still significant) to the solution from the ORCA025 simulation, while INALT10 does not resolve the mesoscale south of $50^{\circ} \mathrm{S}$ and thus is correlated to the ORCA05 solution with a correlation coefficient of 0.92 .

\subsection{The Agulhas Current and the Agulhas Undercurrent}

The AC has been observed in the early 2010s during the Agulhas Current Time-Series Experiment (ACT) utilizing a mooring array, starting between Port Alfred and East London and oriented perpendicular to the coast (Beal et al., 2015) at around $34^{\circ} \mathrm{S}$. The resulting mean velocity structure across the section (Fig. 13f) shows the southwestward-flowing AC being marked by a surface-intensified, near-coastal current with mean velocities up to roughly $1.5 \mathrm{~m} \mathrm{~s}^{-1}$. The current's width is about $220 \mathrm{~km}$. Below the AC, the AUC transports waters northeastward along the continental slope (Beal and Elipot, 2016; Beal et al., 2015).

All configurations simulate a surface-intensified AC with a typical $\mathrm{v}$-shaped pattern. The higher the resolution, the more asymmetric the structure, leading to maximum velocities closer to the coast. The width of the current, as seen in Fig. 13 or calculated according to Beal and Elipot (2016)
Table 9. Correlations of AMOC time series at $34.5^{\circ} \mid 26.5^{\circ} \mathrm{N}$ based on annual averages. Significant correlations at $99 \%$ confidence level are given in bold.

\begin{tabular}{llccc}
\hline & ORCA025 & INALT10 & INALT10x & INALT20 \\
\hline ORCA05 & $\mathbf{0 . 7 5} \mid 0.61$ & $\mathbf{0 . 9 2} \mid \mathbf{0 . 9 8}$ & $\mathbf{0 . 8 8} \mid \mathbf{0 . 9 7}$ & $0.68 \mid 0.56$ \\
ORCA025 & & $\mathbf{0 . 7 1} \mid 0.67$ & $\mathbf{0 . 7 8} \mid \mathbf{0 . 7 1}$ & $\mathbf{0 . 7 1} \mid \mathbf{0 . 7 9}$ \\
INALT10 & & & $\mathbf{0 . 8 5} \mid \mathbf{0 . 9 9}$ & $0.66 \mid 0.65$ \\
INALT10x & & & & $\mathbf{0 . 6 9} \mid \mathbf{0 . 6 9}$ \\
\hline
\end{tabular}

(see Table 10 for all values) is (except for ORCA05) about 20-30 km wider than in observations. Despite the broader current structure, transport is slightly smaller due to weaker surface velocities and the current shows a slightly shallower depth expression. However, if calculated over a 5-year timeframe and fixed reference frame ( $T_{\text {box }}$ according to Beal and Elipot, 2016), the eddy-rich configurations (INALT10(x) and INALT20) simulate the transport within 5\%-10\% of the observed value. The same is true for the representation of the short-term variability provided by the $5 \mathrm{~d}$ standard deviations. Given this prominent short-term variability and interannual fluctuations (see below), the small discrepancy between the eddy-rich configurations and observations is expected. This is also demonstrated by the fact that INALT10 and INALT10x, although simulated at same resolution and parameters, show different transport values. There is no clear resolution dependence of the transport. INALT60, however, simulates a higher transport that is certainly not a representative value because of the limited averaging period and the fact that the model is in a different regime compared to the reference experiments (results are from years 8 to 10 in the spin-up experiments; see also Fig. 14). This is supported by the higher transport in INALT20 for the short period in the spin-up experiment.

Natal Pulses, that episodically deflect the AC from the coast, are simulated in all eddying configurations, which leads to the strong variations of the AC. With respect to the observational reference, one has to note that in the observed years at the ACT array the occurrence of Natal Pulses has been very irregular (four in 2010 and none in 2011 to 2013). Based on SST imagery, for the period 2004 to 2011, 1.6 Natal Pulses per year are found (Rouault and Penven, 2011), while a longer time series covering the satellite period from 1993 to 2012 shows an increase of Natal Pulses per year from 1.3 before 2001 to 2.2 afterwards (Krug and Tournadre, 2012). The eddy-rich reference configurations range between 1.2 and 1.6 Natal Pulses per year in the period 2005 to 2009 , which were defined as a deflection of the maximum velocity in the AC by more than 2 standard deviations off-shore (following $\mathrm{Bi}$ astoch et al., 2018).

The representation of the AUC is clearly dependent on the horizontal grid resolution. Compared to the observed structure (Fig. 13f), the non-eddying simulation in ORCA05 
(a) ORCA05

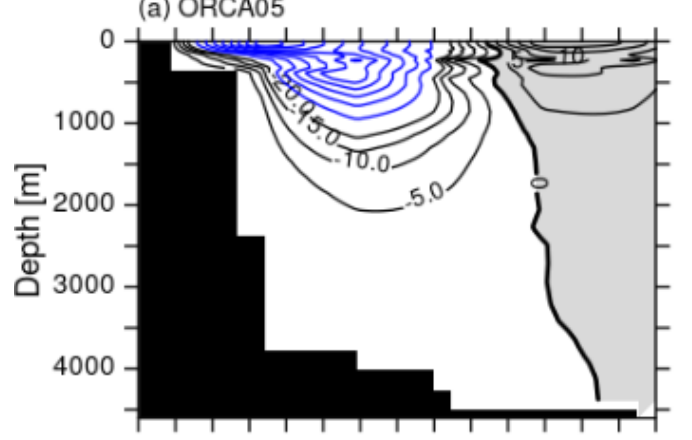

(c) INALT10x

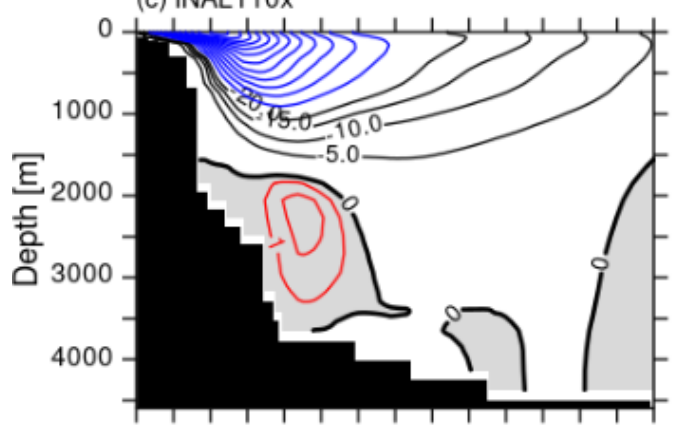

(e) INALT10

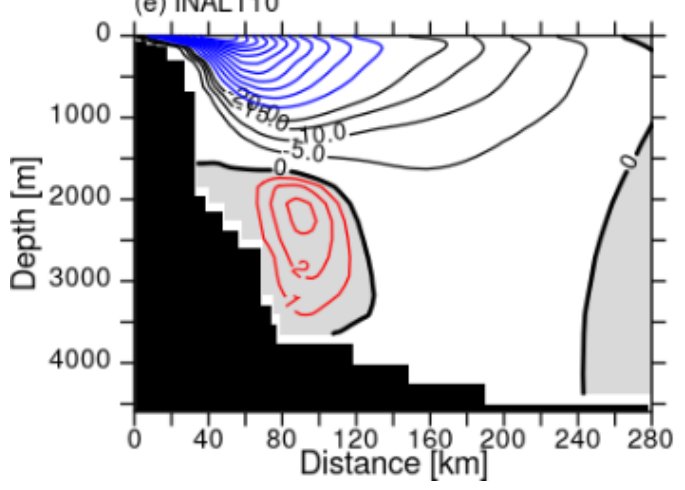

(b) ORCA025

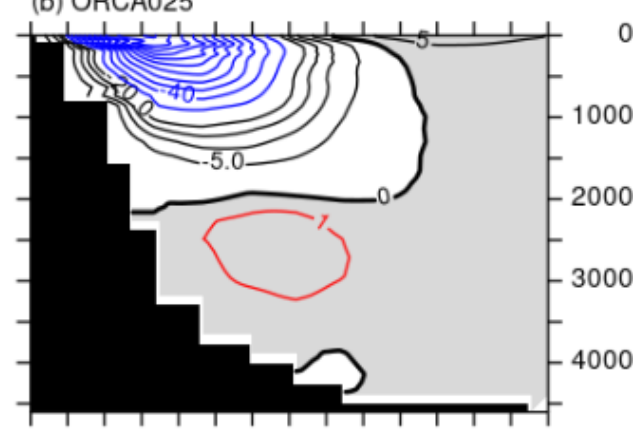

(d) INALT20

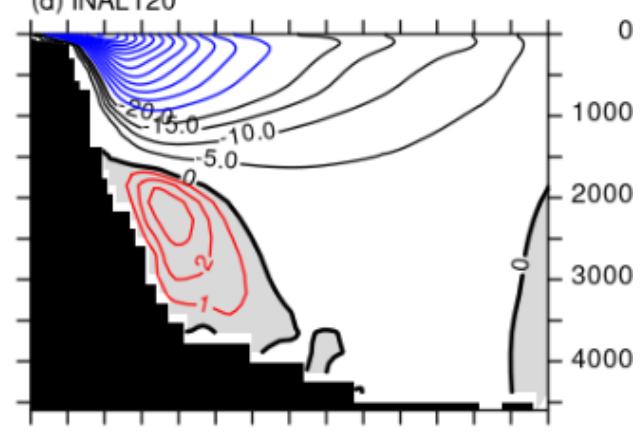

(f) ACT

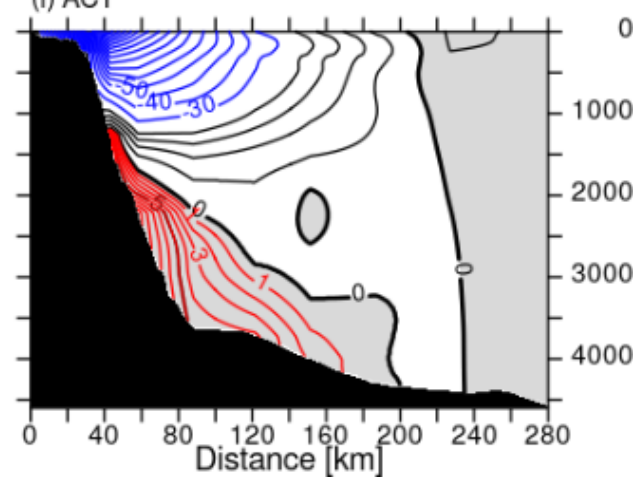

Figure 13. Velocity section perpendicular to the ACT section at $\sim 34^{\circ} \mathrm{S}$ for the simulations (a-e) averaged from 2005 to 2009 and for the observations (f) averaged between 17 April 2010 and 19 February 2013. Southwestward/negative velocities (AC) are shaded in white and northeastward/positive (AUC) in grey; contoured are intervals of $1 \mathrm{~cm} \mathrm{~s}^{-1}$ in red, $5 \mathrm{~cm} \mathrm{~s}^{-1}$ in black and $10 \mathrm{~cm} \mathrm{~s}^{-1}$ in blue.

(Fig. 13a) completely lacks an AUC, while the core of the $\mathrm{AC}$ is further off-shore and weaker than the observed. It also features the strongest off-shore recirculation. ORCA025 (Fig. 13b) is already able to simulate an, admittedly weak, AUC and still shows this relatively weak and off-shore core of the AC, although it is more surface confined. Increasing the resolution leads to an increase in the strength of the undercurrent along with a broadening of the AC. All calculated transport values for the eddy-rich configurations are generally too low (by $40 \%-50 \%$ ) compared to the observations (Beal and Elipot, 2016). This is dependent on potential depth restrictions of the calculation (full depth vs. below $1000 \mathrm{~m}$ ), e.g. to separate the undercurrent structure from the countercurrent appearing during the passing of Natal Pulses (Biastoch et al., 2009a). It has to be noted that simulated (full depth) transport values agree better with the $4.5 \pm 5.2 \mathrm{~Sv}$ reported by Beal (2009), although the latitude at which the transport is calculated and the period taken into account differs between the modelled solutions and observations.

For both the AC and AUC structures, the lateral boundary conditions have only limited impact (Fig. 14d). Although the undercurrent in the free-slip experiment appears closer to the continental slope, the transport does not show a significant difference compared to the reference configuration. However, the influence of the ocean currents on the wind stress calculation has a large impact (Fig. 14e and f). The southeast trade winds in this region typically contribute an additional Ekman component in the direction of the southward-flowing surface current. The increase in AUC transport can be seen as a direct consequence of the enhanced AC. 
(a) INALT20, 1987-1989

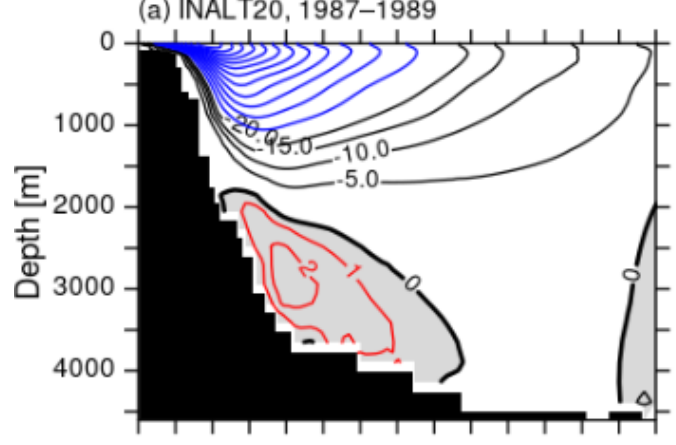

(c) INALT20, NS_RW, 2005-2009

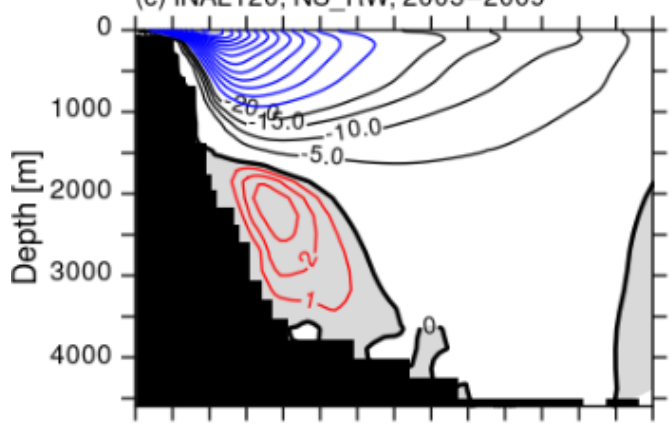

(e) INALT20, FS_AW, 2005-2009

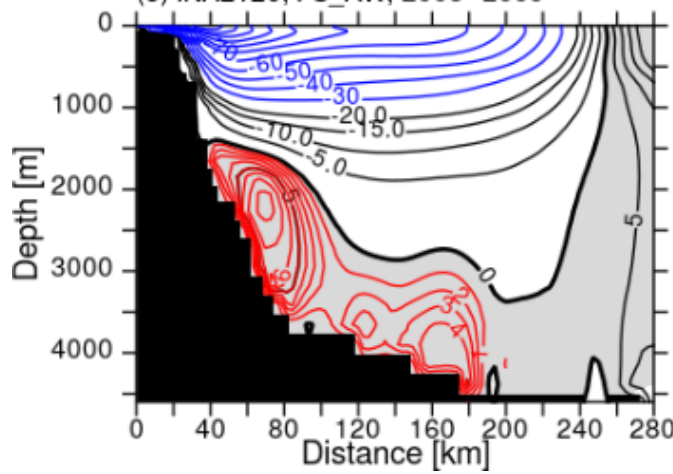

(b) INALT60, 1987-1989

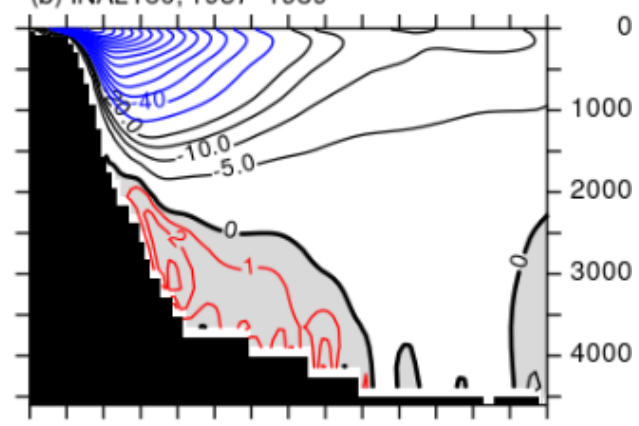

(d) INALT20, FS_RW, 2005-2009

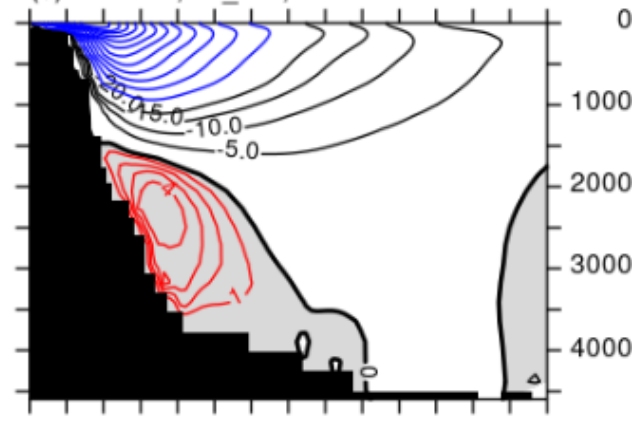

(f) INALT20, FS_PW, 2005-2009

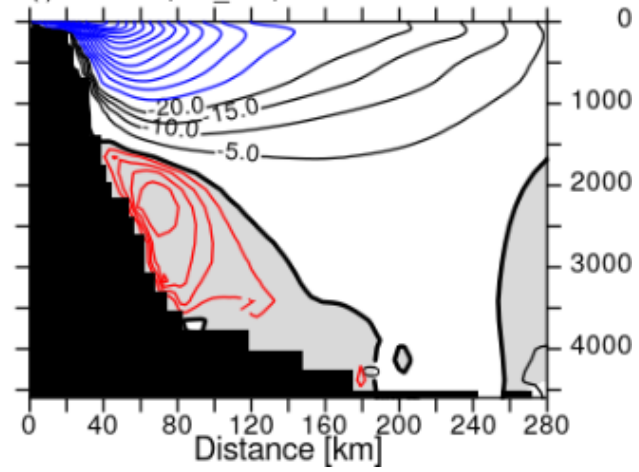

Figure 14. As Fig. 13 but (a) INALT20 and (b) INALT60, averaged over years 8 to 10 (1987-1989) of the spin-up experiments and for the sensitivity experiments in INALT20 averaged over the period 2000-2009 (c-f)

Except for ORCA05, all configurations simulate a substantial interannual variability of the AC and AUC transport (Fig. 15). Rather than a direct relation to the atmospheric forcing, this is a result of the mesoscale variability and Natal Pulses (non-linearity). Earlier simulations with $1 / 10^{\circ}$ configurations under climatological (repeated-year) surface forcing also exhibit a similar degree of interannual variability in comparison to their interannual-varying forced counterparts (Biastoch et al., 2009b; Loveday et al., 2014). It is therefore expected that the individual configurations do not correlate with each other nor are they correlated with the observations. However, all configurations experience a long-term decline of the $\mathrm{AC}$ transport that was already reported by $\mathrm{Bi}-$ astoch et al. (2009b). In contrast to sensitivity experiments presented by Loveday et al. (2014), who show an increase in the Agulhas Current transport in response to increasing trade winds in the Indian Ocean and a symmetrical response, for the tropical gyre circulation, no significant trend in the trade winds in the Indian Ocean can be found in the used CORE forcing. An evaluation of the declining AC trend will be performed elsewhere.

The common wind forcing is also responsible for the seasonal cycle (Fig. 15b), robustly exhibiting low values in austral winter and high values in austral summer in all configurations and consistent with the observations (Krug and Tournadre, 2012; Beal et al., 2015). For the AUC, both amplitudes of short-term and interannual variability are larger than the mean value, which is a result of Natal Pulses (Biastoch et al., 2009a). In agreement with observations, none of the configurations simulate a seasonal cycle of the AUC transport (not shown). 
Table 10. Mean (2005-2009) transport (in Sv) and standard deviations based on $5 \mathrm{~d}$ averages at the ACT section, current widths (in km) and number of Natal Pulses (NPs) per year in the corresponding period. Observational numbers are based on Beal and Elipot (2016). The Agulhas Undercurrent transport is given as the full depth-integrated northeastward transport from the coast to $200 \mathrm{~km}$ off-shore and for the water column below $1000 \mathrm{~m}$.

\begin{tabular}{lrrrr}
\hline & AC (in Sv) & AC width (in km) & AUC (in Sv) (full depth | below 1000 m) & NPs (year $^{-1}$ ) \\
\hline Observations & $77 \pm 31$ & 219 & $10.7 \pm 9.8 \mid 8.6 \pm 6.7$ & 1.3 \\
\hline ORCA05 & $63.3 \pm 3.6$ & 203 & $0.1 \pm 0.1 \mid 0$ & 0 \\
ORCA025 & $61.3 \pm 22.1$ & 246 & $4.2 \pm 5.7 \mid 3.2 \pm 4.3$ & 0.4 \\
INALT10 & $70.0 \pm 28.9$ & 236 & $6.0 \pm 6.4 \mid 4.8 \pm 5.1$ & 1.6 \\
INALT10x & $76.3 \pm 32.4$ & 247 & $6.1 \pm 8.1 \mid 5.3 \pm 6.3$ & 1.2 \\
INALT20 NS_RW & $76.3 \pm 30.7$ & 239 & $6.9 \pm 8.3 \mid 5.7 \pm 6.4$ & 1.4 \\
\hline INALT20 FS_RW & $73.6 \pm 23.8$ & 237 & $6.6 \pm 6.2 \mid 5.7 \pm 5.0$ & 1.4 \\
INALT20 FS_AW & $105.3 \pm 89.1$ & 205 & $7.3 \pm 8.2 \pm 0.6 \mid 14.9 \pm 23.5$ & 2.2 \\
INALT20 FS_PW & $86.5 \pm 29.5$ & 250 & $6.2 \pm 8.1 \mid 5.2 \pm 6.5$ & 1.4 \\
\hline INALT20 (1987-1989)* & $86.3 \pm 32.6$ & 234 & $7.1 \pm 10.3 \mid 5.6 \pm 7.7$ & 2.0 \\
INALT60 (1987-1989)* & $80.8 \pm 28.4$ & 203 & & 0.3 \\
\hline
\end{tabular}

* Years of the lower two rows refer to the spin-up periods.

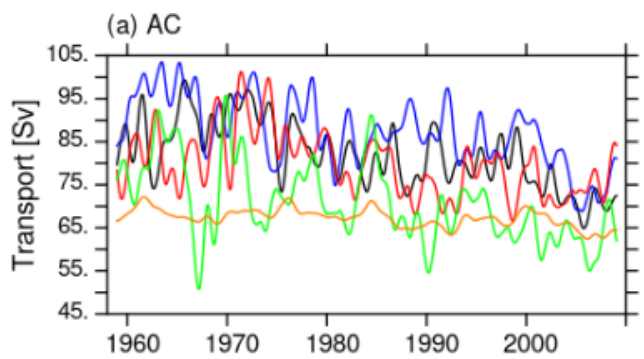

(c) AUC full depth

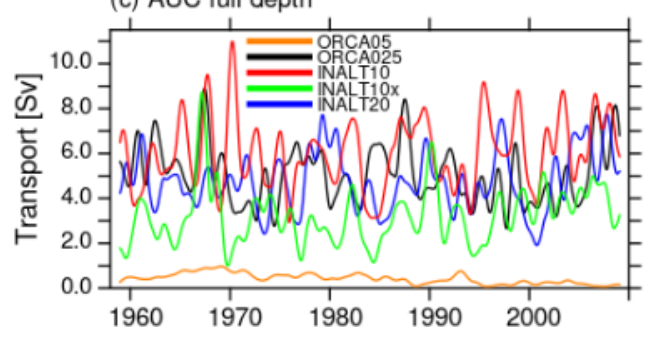

(b) Annual cycle

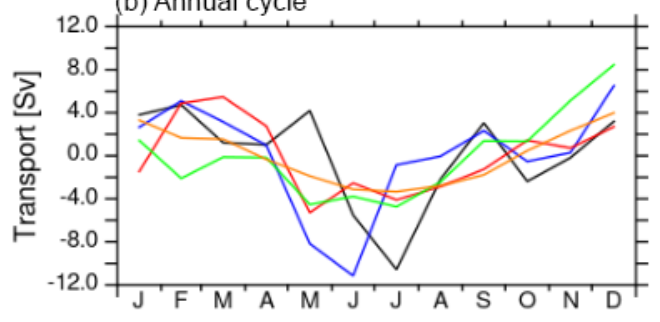

(d) AUC below $1000 \mathrm{~m}$

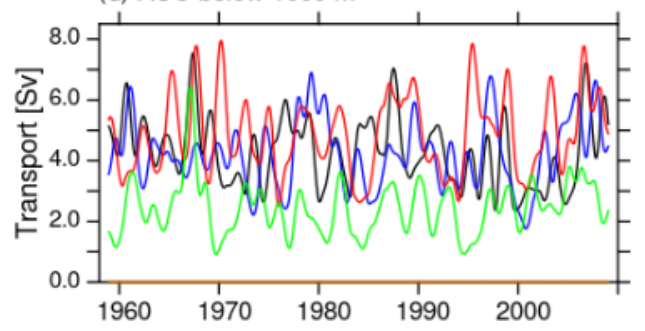

Figure 15. Agulhas Current transport time series (a) and annual cycle of transport anomalies (b) (in Sv). Agulhas Undercurrent transport (in $\mathrm{Sv}$ ) defined as the full depth-integrated (c) and below $1000 \mathrm{~m}$ depth (d) northeastward velocity across the ACT section between the coast and $200 \mathrm{~km}$ off-shore.

\subsection{Agulhas leakage}

The flow from the Indian Ocean to the Atlantic Ocean through the Agulhas system is given by the Agulhas leakage. Due to high spatiotemporal variability, it is typically calculated in a Lagrangian way (e.g. Biastoch et al., 2009b). Virtual particles are released at a section across the AC at $32^{\circ} \mathrm{S}$, continuously over 1 year and advected forward using the $5 \mathrm{~d}$ time-varying three-dimensional flow field over a total of 5 years. Each particle is tagged with an initial transport that is kept constant during the integration. The transport of the particles that cross the Good Hope line (yellow in
Fig. 16) is summed up and referred to as Agulhas leakage; those crossing the $35^{\circ} \mathrm{E}$ meridian are defined as the Agulhas Return Current. This is done for every single year of each model experiment, leading to annual time series of the $\mathrm{AC}$, the Agulhas Return Current and Agulhas leakage transport. This method is a well-established methodology for ocean models (Durgadoo et al., 2013; Biastoch et al., 2009b; Biastoch et al., 2015), mimicking the sparse observations from surface and intermediate depth floats (Richardson, 2007).

In contrast to the ACT section described above, the AC here exhibits much more similarities across all experiments, with only INALT10 being generally weaker. The reason for 
(a) Lagrangian design

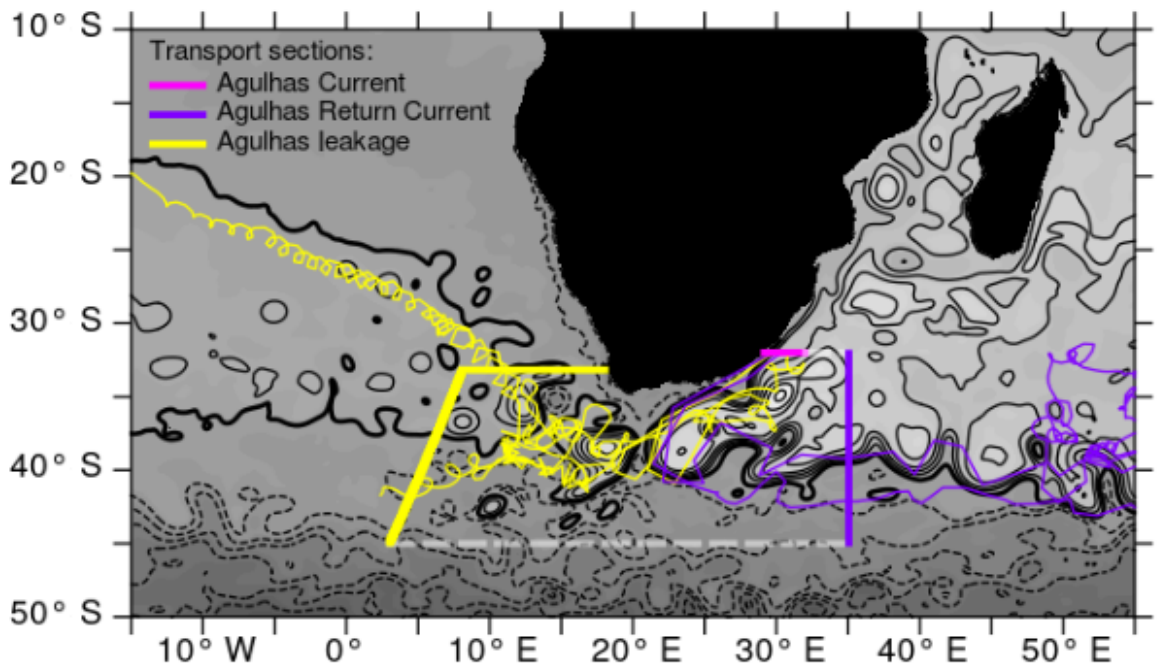

(b) Agulhas Current

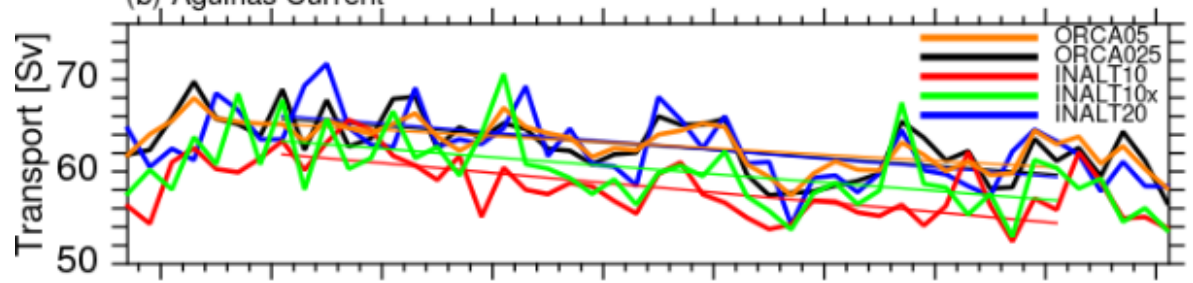

(c) Agulhas Return Current

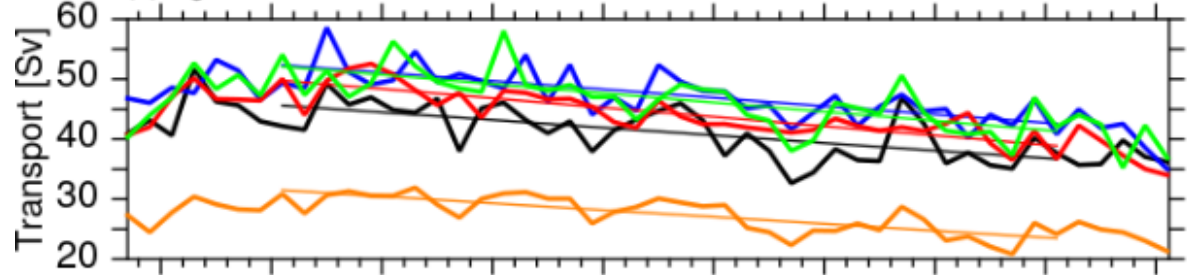

(d) Agulhas leakage

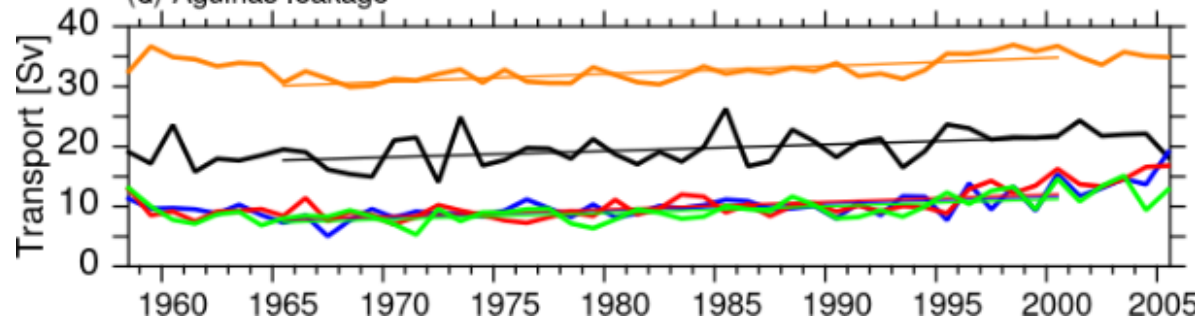

Figure 16. Lagrangian design (a) and transport time series (in Sv) of the Agulhas Current (b; transport across the magenta line in panel a), Agulhas Return Current (c, transport across the purple line in panel a) and leakage (d, transport across the yellow line in panel a) from the Lagrangian experiments. The shading and contours in panel (a) are a snapshot of SSH as simulated in INALT20. The yellow and purple trajectories indicate exemplary paths from the release to the sampling sections.

this behaviour is that at this latitude $\left(32^{\circ} \mathrm{S}\right)$ the $\mathrm{AC}$ is more stable and linear (Bryden et al., 2005). Further south at ACT, a meandering of the current takes place, together with local recirculations.

ORCA025, INALT10x and INALT20 are subject to a comparable decline of the AC transport of around $1.8 \mathrm{~Sv}$ per decade, while the trend in ORCA05 is lower and in INALT10 it is slightly higher (Table 11).

Excluding ORCA05, $60 \%$ (ORCA025) to $70 \%$ (INALT configurations) of the initial $\mathrm{AC}$ transport retroflects and flows back into the Indian Ocean, along the Agulhas Return Current. ORCA05 (and to a certain degree also ORCA025) features a too-strong Agulhas leakage compared to the 
Table 11. Mean (1995-2005) transport (in Sv) and linear trends from 1965 to 2000 (in Sv per decade) for the Agulhas Current (AC), Agulhas Return Current (AR) and Agulhas leakage (AL) as simulated in the Lagrangian experiments.

\begin{tabular}{lccc}
\hline & $\mathrm{AC}$ & $\mathrm{AR}$ & $\mathrm{AL}$ \\
\hline ORCA05 & $61.3 \mid-1.3$ & $23.6 \mid-2.3$ & $35.5 \mid 1.1$ \\
ORCA025 & $60.8 \mid-1.7$ & $37.0 \mid-2.6$ & $22.0 \mid 1.1$ \\
INALT10 & $56.8 \mid-2.1$ & $39.0 \mid-3.1$ & $13.9 \mid 1.2$ \\
INALT10x & $57.0 \mid-1.8$ & $41.0 \mid-3.1$ & $12.2 \mid 1.3$ \\
INALT20 & $60.3 \mid-1.9$ & $42.0 \mid-2.8$ & $12.9 \mid 1.1$ \\
\hline
\end{tabular}

canonical number of $15 \mathrm{~Sv}$ in the upper $1000 \mathrm{~m}$ estimated by Richardson (2007). This resolution dependence of Agulhas leakage is well documented and a result of adequately represented mesoscale processes (e.g. Durgadoo et al., 2013). The INALT configurations simulate an Agulhas leakage in the range of 12 to $14 \mathrm{~Sv}$ and are thus slightly lower compared to the observational estimate. Quite robust among all model configurations is the upward trend of Agulhas leakage between 1960s and 2000s, mainly a result of the strengthening of the Southern Hemisphere westerlies in the common wind forcing (Durgadoo et al., 2013). The simulated trend of 1.1-1.3 Sv per decade is in the range of the observationally based index provided through east-west gradients of sea surface temperature (Biastoch et al., 2015).

\section{Conclusions}

A series of nested global ocean model configurations, called the INALT family, has been established with horizontal resolutions of $1 / 10,1 / 20$ and $1 / 60^{\circ}$ in the South Atlantic and western Indian oceans. It has been shown that already at $1 / 10^{\circ}$ horizontal resolution it is possible to simulate the eddygenerating instability processes in the source regions of the Agulhas Current and in the greater Agulhas Current system. An open question remains whether $1 / 10^{\circ}$ is already sufficient to represent the full range of mesoscale processes. Given the decrease of the baroclinic Rossby radius towards higher latitudes, it follows that at least $1 / 20^{\circ}$, probably even higher, resolution is required to represent mesoscale processes in the Southern Ocean.

The use of well-established global configurations as hosts for the nested configurations provides an important prerequisite. The corresponding configurations, ORCA05 and ORCA025, determine the embedment of the large-scale transport such as the Atlantic meridional overturning circulation, the supergyre and the Antarctic Circumpolar Current. It is demonstrated that the temporal variability of these measures in the hosts of the nested configurations is correlated with the respective un-nested configurations on interannual to decadal timescales. Nevertheless, the mesoscale dynamics in the nests also feed back to the global scale.
The representation of mesoscale variability in the region covered by the high-resolution nests improves with increasing horizontal resolution. In midlatitudes, the configurations at $1 / 10^{\circ}$, INALT10 and INALT10x, already capture most of the observed variability, while at higher latitudes, INALT20 at $1 / 20^{\circ}$ resolution shows a more realistically simulated variability, not only due to the high resolution in the nested region but also due to the eddying resolution on the host grid.

Resolving mesoscale processes leads to a more realistic representation of the highly variable Agulhas Current system. Upstream the Agulhas Current, the mean barotropic transport through the Mozambique Channel is comparable to observations in the un-nested configurations (ORCA05 and ORCA025) at the expense of non-existent mesoscale eddies. The high-resolution nests properly simulate the mesoscale variability, while the simulated transport is significantly weaker. This points to an under-representation of the eddy transport in the Mozambique Channel. Despite the offset in the mean, all model configurations reproduce the observed seasonal cycle in the transport through the Mozambique Channel and are significantly correlated with observations at monthly timescales.

The Agulhas Current transport itself increases with increasing resolution up to $1 / 10^{\circ}$, while beyond it slightly decreases. The transport of Agulhas Undercurrent, located on the continental slope below the Agulhas Current, further increases through all model resolutions. Both currents become more realistic in their mean transport and spatial structure in the eddy-rich configurations. Due to the bathymetric impact on the undercurrent, INALT60 shows an additional level of improvement against INALT20. It was shown that transport estimates and current structure realism not only depend on resolution but obviously also on details of the numerical settings in terms of boundary conditions. Altering lateral boundary conditions and the use of ocean currents in the wind stress calculation leads to a large range in the simulated transport. In addition, strong intrinsic variations lead to interannual variations, preventing a proper comparison with the limited observational estimates of the currents. However, on longer timescales, the $\mathrm{AC}$ transport shows comparable trends among the different configurations.

Downstream the Agulhas Current, where it separates into the Agulhas Return Current flowing back into the Indian Ocean and the Agulhas leakage that transports Indian Ocean waters into the Atlantic Ocean, all eddy-active configurations show a comparable behaviour. The majority of the transport $(60 \%$ to $70 \%)$ retroflects into the Indian Ocean, and only a minor portion finds its way into the Atlantic at comparable levels. The amount of Agulhas leakage simulated within the eddying configurations resembles the estimate from the sparse observations. Although the annual transport of the Agulhas Current, the Agulhas Return Current and the Agulhas leakage is naturally decorrelated among the different configurations because of the non-linearity involved, on longer 
timescales and as a result of the common forcing, they show comparable trends.

In addition to the greater Agulhas Current system, the representation of the western boundary currents in the South Atlantic, the Malvinas and North Brazil currents shows a general improvement with increasing model resolutions in structure and mean transport. The experiments also emphasize the importance of mesoscale processes in the Atlantic sector of the Southern Ocean on the representation of the Malvinas Current.

The resulting Atlantic meridional overturning circulation is robust concerning its structure among the different configurations with only the Antarctic Bottom Water cell showing a pronounced dependency on the resolution in the Atlantic and western Indian Ocean sectors of the Southern Ocean. The Antarctic Bottom Water cell is stronger and vertically more extended in INALT10x and INALT20 when compared to the other configurations. The mean transport at the meridional locations of the observational measurement sites SAMBA in the South Atlantic and RAPID in the North Atlantic only shows a slight increase with increasing resolution among the eddying configurations, whereas ORCA05 stands out with significantly weaker transport. Nevertheless, the observed mean transport at both locations is still underestimated. The mean transport of the Atlantic meridional overturning circulation consequently appears to be primarily dependent on driving factors in the North Atlantic, while its interannual variability is strongly forcing dependent.

Most of the mesoscale variability in the greater Agulhas Current region and the South Atlantic is simulated comparably at $1 / 10$ and $1 / 20^{\circ}$ resolution. The comparison between INALT10 and INALT10x can be used to isolate and study the Southern Ocean influence on the Agulhas dynamics. However, a weakness of ORCA05 providing the host for the two configurations at $1 / 10^{\circ}$ remains: even in INALT10x, the variability entering the South Atlantic through the Drake Passage is absent, in contrast to INALT20, where the host configuration already simulates an eddying Antarctic Circumpolar Current. Comparing the eddy-poor ORCA05 and eddy-rich $1 / 10^{\circ}$ configurations enables to specifically investigate the impact of resolving the mesoscale on a variety of physical processes.

The INALT family provides a consistent set of ocean model configurations. It allows to study a number of regional aspects, such as the cold vs. warm water route on the upper limb of the Atlantic meridional overturning circulation (Rühs et al., 2019) or the spreading of water masses in the South Atlantic (Tim et al., 2018). The range of resolution allows to address the impact of the mesoscale on the mean flow as well as mesoscale dynamics itself. INALT60 will be used to explore the way towards submesoscale processes. The inclusion of the Southern Ocean sector, by comparing INALT10x and INALT10, allows to isolate the impact of Southern Ocean dynamics on the greater Agulhas Current system. INALT10 and INALT10x provide the oceanic basis for the coupling with an active atmosphere in the new Flexible Ocean Climate Infrastructure (FOCI; Matthes et al., 2019).

Code and data availability. Data are available at https: //data.geomar.de/thredds/catalog/open_access/schwarzkopf_et_al_ 2019_gmd/catalog.html (last access: 10 July 2019; Schwarzkopf, 2019). The model simulations are based on NEMO version 3.6 https://forge.ipsl.jussieu.fr/nemo/svn/NEMO/releases/release-3.6 (last access: 10 July 2019; Madec and the NEMO team, 2014) (revision 6721). The AGRIF library is part of the NEMO release but maintained by INRIA. Documentation on the library itself as well as access to the code are available at http://agrif.imag.fr/ (last access: 10 July 2019; Debreu et al., 2008).

Author contributions. FUS developed the family of INALT configurations, performed all experiments in INALT20(r) and INALT60 and conducted all analyses. FUS and AB jointly wrote the manuscript. JC supported the model development as part of the NEMO system team. JH performed the model experiments in ORCA05 and INALT10(x); JKR performed the model experiments in ORCA025. MMS set up and supported the model environment for all experiments. RS contributed the submesoscale part of the paper. All authors were involved at different stages of the establishment of the model family and contributed to the final manuscript.

Competing interests. The authors declare that they have no conflict of interest.

Acknowledgements. All model simulations have been performed at the North-German Supercomputing Alliance (HLRN). We gratefully acknowledge the work by the NEMO system team, and especially thank Rachid Benshila for his assistance during the model setup phase. We thank Tobias Schulzki for generating Fig. 1. Our thanks also go to Jenny Ullgren and NIOZ Royal Netherlands Institute for Sea Research for providing the observed Mozambique Channel transport time series (LOCO). The authors also thank two anonymous reviewers for investing their time in improving the manuscript.

Financial support. This research has been supported by the German Federal Ministry of Education and Research (grant nos. SPACES-AGULHAS (03F0750A) and SPACES-CASISAC (03F0796A)). Jonathan V. Durgadoo acknowledges funding from the Helmholtz-Gemeinschaft and the GEOMAR Helmholtz Centre for Ocean Research Kiel (grant no. IV014/GH018).

Review statement. This paper was edited by Paul Halloran and reviewed by two anonymous referees. 


\section{References}

Ansorge, I. J. and Lutjeharms, J. R. E.: Direct observations of eddy turbulence at a ridge in the Southern Ocean, Geophys. Res. Lett., 32, L14603, https://doi.org/10.1029/2005GL022588, 2005.

Ansorge, I. J., Baringer, M. P., Campos, E., Dong, S., Fine, R. A., Goni, G., Meinen, C., Rerez, R. C., Piola, A. R., Roberts, M. J., Speich, S., Sprintall, J., Terre, T., and Van Den Berg, M. A.: Basin-Wide Oceanographic Array Bridges the South Atlantic, EOS, 95, 53-54, https://doi.org/10.1002/2014EO060001, 2014.

Arakawa, A. and Hsu, Y.-J. G.: Energy Conserving and Potential-Enstrophy Dissipating Schemes for the Shallow Water Equations, Mon. Weather Rev., 118, 1960-1969, https://doi.org/10.1175/15200493(1990)118<1960:ECAPED>2.0.CO;2, 1990.

Arhan, M., Mercier, H., and Lutjeharms, J. R. E.: The disparate evolution of three Agulhas rings in the South Atlantic Ocean, J. Geophys. Res., 104, 20987-21005, https://doi.org/10.1029/1998JC900047, 1999.

Arhan, M., Mercier, H., and Park, Y.-H.: On the deep water circulation of the eastern South Atlantic Ocean, Deep Sea Res. I, 50, 889-916, https://doi.org/10.1016/S0967-0637(03)00072-4, 2003

Artana, C., Ferrari, R., Koenig, Z., Sennéchael, N., Saraceno, M., Piola, A. R., and Provost, C.: Malvinas Current volume transport at $41^{\circ} \mathrm{S}$ : A 24 yearlong time series consistent with mooring data from 3 decades and satellite altimetry, J. Geophys. Res., 123, 378-398, https://doi.org/10.1002/2017JC013600, 2018.

Backeberg, B., Johannessen, J., Bertino, L., and Reason, C.: The greater Agulhas Current system: An integrated study of its mesoscale variability, J. Operat. Oceanogr., 1, 29-44, https://doi.org/10.1080/1755876X.2008.11020093, 2008.

Barnier, B., Madec, G., Penduff, T., Molines, J.-M., Treguier, A.M., Le Sommer, J., Beckmann, A., Biastoch, A., Böning, C., Dengg, J., Derval, C., Durand, E., Gulev, S., Remy, E., Talandier, C., Theetten, S., Maltrud, M., McClean, J., and De Cuevas, B.: Impact of partial steps and momentum advection schemes in a global ocean circulation model at eddy-permitting resolution, Ocean Dynam., 56, 543-567, https://doi.org/10.1007/s10236006-0082-1, 2006.

Beal, L. and Elipot, S.: Broadening not strengthening of the Agulhas Current since the early 1990s, Nature, 540, 570-573, https://doi.org/10.1038/nature19853, 2016.

Beal, L. M.: A Time Series of Agulhas Undercurrent Transport, J. Phys. Oceanogr., 39, 2436-2450, https://doi.org/10.1175/2009JPO4195.1, 2009.

Beal, L. M., de Ruijter, W. P. M., Biastoch, A., Zahn, R., SCOR/WCRP/IAPSO Working Group 136, Cronin, M., Hermes, J., Lutjeharms, J. R. E., Quartly, G., Tozuka, T., Baker-Yeboah, S., Bornman, T., Cipollini, P., Dijkstra, H., Hall, I., Park, W., Peeters, F., Penven, P., Ridderinkhof, H., and Zinke, J.: On the role of the Agulhas system in ocean circulation and climate, Nature, 472, 429-436, https://doi.org/10.1038/nature09983, 2011.

Beal, L. M., Elipot, S., Houk, A., and Leber, G. M.: Capturing the Transport Variability of a Western Boundary Jet: Results from the Agulhas Current Time-Series Experiment (ACT), J. Phys. Oceanogr., 45, 1302-1324, https://doi.org/10.1175/JPOD-14-0119.1, 2015.

Beckmann, A. and Döscher, R.: A Method for Improved Representation of Dense Water Spreading over To- pography in Geopotential-Coordinate Models, J. Phys. Oceanogr., 27, 581-591, https://doi.org/10.1175/15200485(1997)027<0581:AMFIRO>2.0.CO;2, 1997.

Behrens, E., Biastoch, A., and Böning, C. W.: Spurious AMOC trends in global ocean sea-ice models related to subarctic freshwater forcing, Ocean Modell., 69, 39-49, https://doi.org/10.1016/j.ocemod.2013.05.004, 2013.

Behrens, E., Våge, K., Harden, B., Biastoch, A., and Böning, C. W.: Composition and variability of the Denmark Strait Overflow Water in a high-resolution numerical model hindcast simulation, J. Geophys. Res., 122, 2830-2846, https://doi.org/10.1002/2016JC012158, 2017.

Biastoch, A. and Böning, C. W.: Anthropogenic impact on Agulhas leakage, Geophys. Res. Lett., 40, 1138-1143, https://doi.org/10.1002/grl.50243, 2013.

Biastoch, A., Böning, C., and Lutjeharms, J.: Agulhas leakage dynamics affects decadal variability in Atlantic overturning circulation, Nature, 456, 489-492, https://doi.org/10.1038/nature07426, 2008a.

Biastoch, A., Böning, C. W., Getzlaff, J., Molines, J.-M., and Madec, G.: Causes of interannual-decadal variability in the meridional overturning circulation of the midlatitude North Atlantic Ocean, J. Climate, 21, 6599-6615, https://doi.org/10.1175/2008JCLI2404.1, 2008b.

Biastoch, A., Lutjeharms, J. R. E., Böning, C. W., and Scheinert, M.: Mesoscale perturbations control inter-ocean exchange south of Africa, Geophys. Res. Lett., 35, L20602, https://doi.org/10.1029/2008GL035132, 2008c

Biastoch, A., Beal, L. M., Lutjeharms, J. R. E., and Casal, T. G. D.: Variability and Coherence of the Agulhas Undercurrent in a High-Resolution Ocean General Circulation Model, J. Phys. Oceanogr., 39, 2417-2435, https://doi.org/10.1175/2009JPO4184.1, 2009a.

Biastoch, A., Böning, C. W., Schwarzkopf, F. U., and Lutjeharms, J. R. E.: Increase in Agulhas leakage due to poleward shift of Southern Hemisphere westerlies, Nature, 462, 495-498, https://doi.org/10.1038/nature08519, 2009b.

Biastoch, A., Durgadoo, J. V., Morrison, A., van Sebille, E., Weijer, W., and Griffies, S.: Atlantic multi-decadal oscillation covaries with Agulhas leakage, Nat. Commun., 6, 10082, https://doi.org/10.1038/ncomms10082, 2015.

Biastoch, A., Sein, D., Durgadoo, J. V., Wang, Q., and Danilov, S.: Simulating the Agulhas system in global ocean models - nesting vs. multi-resolution unstructured meshes, Ocean Modell., 121, 117-131, https://doi.org/10.1016/j.ocemod.2017.12.002, 2018.

Blanke, B. and Delecluse, P.: Variability of the Tropical Atlantic Ocean Simulated by a General Circulation Model with Two Different Mixed-Layer Physics, J. Phys. Oceanogr., 23, 1363-1388, https://doi.org/10.1175/15200485(1993)023<1363:VOTTAO>2.0.CO;2, 1993.

Boebel, O., Lutjeharms, J., Schmid, C., Zenk, W., Rossby, T., and Barron, C.: The Cape Cauldron: A regime of turbulent inter-ocean exchange, Deep Sea Res. II, 50, 57-86, https://doi.org/10.1016/S0967-0645(02)00379-X, 2003.

Böning, C., Behrens, E., Biastoch, A., and Bamber, J.: Emerging impact of Greenland meltwater on deepwater formation in the North Atlantic Ocean, Nat. Geosci., 9, 523-527, https://doi.org/10.1038/ngeo2740, 2016. 
Bourdallé-Badie, R. and Treguier, A.: A climatology of runoff for the global ocean-ice model ORCA025, Mercator-Ocean reference, MOO-RP-425-365-MER, 2006.

Bryden, H., Beal, L., and Duncan, L.: Structure and Transport of theAgulhas Current and its temporal variability, J. Oceanogr., 61, 479-492, https://doi.org/10.1007/s10872-005-0057-8, 2005.

Casal, T. G. D., Beal, L. M., and Lumpkin, R.: A North Atlantic deep-water eddy in the Agulhas Current system, Deep Sea Res. I, 53, 1718-1728, https://doi.org/10.1016/j.dsr.2006.08.007, 2006.

Chassignet, E. P., Xu, X., Chassignet, E. P., and Xu, X.: Impact of Horizontal Resolution $\left(1 / 12^{\circ}\right.$ to $\left.1 / 50^{\circ}\right)$ on Gulf Stream Separation, Penetration, and Variability, J. Phys. Oceanogr., 47, 19992021, https://doi.org/10.1175/JPO-D-17-0031.1, 2017.

Chelton, D. B., DeSzoeke, R. A., Schlax, M. G., El Naggar, K., and Siwertz, N.: Geographical Variability of the First Baroclinic Rossby Radius of Deformation, J. Phys. Oceanogr., 28, 433-460, https://doi.org/10.1175/15200485(1998)028<0433:GVOTFB>2.0.CO;2, 1998.

Cronin, M. F., Tozuka, T., Biastoch, A., Durgadoo, J. V., and Beal, L. M.: Prevalence of strong bottom currents in the greater Agulhas system, Geophys. Res. Lett., 40, 1772-1776, https://doi.org/10.1002/grl.50400, 2013.

Cunningham, S., Alderson, S., and King, B.: Transport and Variability of the Antarctic Circumpolar Current in Drake Passage, J. Geophys. Res., 108, 8084, https://doi.org/10.1029/2001JC001147, 2003.

de Boyer Montégut, C., Madec, G., Fischer, A. S., Lazar, A., and Iudicone, D.: Mixed layer depth over the global ocean: An examination of profile data and a profilebased climatology, J. Geophys. Res., 109, C12003, https://doi.org/10.1029/2004JC002378, 2004.

de Ruijter, W. P. M., Biastoch, A., Drijfhout, S. S., Lutjeharms, J. R. E., Matano, R. P., Pichevin, T., van Leeuwen, P. J., and Weijer, W.: Indian-Atlantic interocean exchange: Dynamics, estimation and impact, J. Geophys. Res., 104, 20885-20910, https://doi.org/10.1029/1998JC900099, 1999a.

de Ruijter, W. P. M., van Leeuwen, P. J., and Lutjeharms, J. R. E.: Generation and evolution of Natal Pulses, solitary meanders in the Agulhas Current, J. Phys. Oceanogr., 29, 3043-3055, https://doi.org/10.1175/15200485(1999)029<3043:GAEONP>2.0.CO;2, 1999 b.

Debreu, L., Vouland, C., and Blayo, E.: AGRIF: Adaptive grid refinement in Fortran, Comput. Geosci., 34, 8-13, https://doi.org/10.1016/j.cageo.2007.01.009, 2008.

DiMarco, S. F., Chapman, P., Nowlin, W. D., Hacker, P., Donohue, K., Luther, M., Johnson, G. C., and Toole, J.: Volume transport and property distributions of the Mozambique Channel, Deep Sea Res. II, 49, 1481-1511, https://doi.org/10.1016/S09670645(01)00159-X, 2002.

Donohue, K., Tracey, K., Watts, D., Chidichimo, M. P., and Chereskin, T.: Mean Antarctic Circumpolar Current transport measured in Drake Passage, Geophys. Res. Lett., 43, 11760-11767, https://doi.org/10.1002/2016GL070319, 2016.

Durgadoo, J., Loveday, B., Reason, C., Penven, P., and Biastoch, A.: Agulhas Leakage Predominantly Responds to the Southern Hemisphere Westerlies, J. Phys. Oceanogr., 43, 2113-2131, https://doi.org/10.1175/JPO-D-13-047.1, 2013.
Durgadoo, J. V., Rühs, S., Biastoch, A., and Böning, C. W.: Indian Ocean sources of Agulhas leakage, J. Geophys. Res., 122, 34813499, https://doi.org/10.1002/2016JC012676, 2017.

Evans, G. R., McDonagh, E. L., King, B. A., Bryden, H. L., Bakker, D., Brown, P. J., Schuster, U., Speer, K. G., and van Heuven, S. M. A. C.: South Atlantic interbasin exchanges of mass, heat, salt and anthropogenic carbon, Progr. Oceanogr., 151, 62-82, https://doi.org/10.1016/j.pocean.2016.11.005, 2017.

Farrow, D. and Stevens, D.: A new tracer advection scheme for Bryan and Cox type ocean general circulation models, J. Phys. Oceanogr., 25, 1731-1741, https://doi.org/10.1175/15200485(1995)025<1731:ANTASF>2.0.CO;2, 1995.

Fichefet, T. and Maqueda, M. M.: Sensitivity of a global sea ice model to the treatment of ice thermodynamics and dynamics, J. Geophys. Res., 102, 12609-12646, https://doi.org/10.1029/97JC00480, 1997.

Frajka-Williams, E., Cunningham, S. A., Bryden, H., and King, B. A.: Variability of Antarctic Bottom Water at $24.5^{\circ} \mathrm{N}$ in the Atlantic, J. Geophys. Res., 116, C12003, https://doi.org/10.1029/2011JC007168, 2011.

Fricourt, Y., Drijfhout, S., Blanke, B., and Speich, S.: Water Mass Export from Drake Passage to the Atlantic, Indian, and Pacific Oceans: A Lagrangian Model Analysis, J. Phys. Oceanogr., 35, 1206-1222, https://doi.org/10.1175/JPO2748.1, 2005.

Garzoli, S. L., Baringer, M. O., Dong, S., Perez, R. C., and Yao, Q. South Atlantic meridional fluxes, Deep Sea Res. I, 71, 21-32, https://doi.org/https://doi.org/10.1016/j.dsr.2012.09.003, 2013.

Gent, P. R. and McWilliams, J.: Isopycnal Mixing in Ocean Circulation Models, J. Phys. Oceanogr., 20, 150-155, https://doi.org/10.1175/15200485(1990)020<0150:IMIOCM>2.0.CO;2, 1990.

Goni, G., Bringas, F., and DiNezio, P. N.: Observed low frequency variability of the Brazil Current front, J. Geophys. Res., 116, C10037, https://doi.org/10.1029/2011JC007198, 2011.

Gordon, A. L.: Interocean Exchange of Thermocline Water, J. Geophys. Res., 91, 5037-5046, https://doi.org/10.1029/JC091iC04p05037, 1986.

Gordon, A. L.: Oceanography: The brawniest retroflection, Nature, 421, 904-905, https://doi.org/10.1038/421904a, 2003.

Griffies, S. M., Biastoch, A., Böning, C. W., Bryan, F., Danabasoglu, G., Chassignet, E. P., England, M. H., Gerdes, R., Haak, H., Hallberg, R. W., Hazeleger, W., Jungclaus, J., Large, W. G., Madec, G., Pirani, A., Samuels, B. L., Scheinert, M., Sen Guptay, A., Severijns, C. A., Simmons, H. L., Treguier, A.M., Winton, M., Yeager, S., and Yin, J.: Coordinated OceanIce Reference Experiments (COREs), Ocean Modell., 26, 1-46, https://doi.org/10.1016/j.ocemod.2008.08.007, 2009.

Hermes, J., Reason, C., and Lutjeharms, J.: Modeling the Variability of the Greater Agulhas Current System, J. Climate, 20, 31313146, https://doi.org/10.1175/JCLI4154.1, 2007.

Hollingsworth, A., Kållberg, P., Renner, V., and Burridge, D. M.: An internal symmetric computational instability, Q. J. Roy. Meteorol. Soc., 109, 417-428, https://doi.org/10.1002/qj.49710946012, 1983.

Holton, L., Deshayes, J., Backeberg, B. C., Loveday, B. R., Hermes, J. C., and Reason, C. J. C.: Spatio-temporal characteristics of Agulhas leakage: a model inter-comparison study, Clim. Dynam., 48, 2107-2121, https://doi.org/10.1007/s00382-016-3193$5,2017$. 
Hummels, R., Brandt, P., Dengler, M., Fischer, J., Araujo, M., Veleda, D., and Durgadoo, J. V.: Interannual to decadal changes in the western boundary circulation in the Atlantic at $11 \mathrm{dg}$ S, Geophys. Res. Lett., 42, 7615-7622, https://doi.org/10.1002/2015GL065254, 2015.

Krug, M. and Tournadre, J.: Satellite observations of an annual cycle in the Agulhas Current, Geophys. Res. Lett., 39, C10037, https://doi.org/10.1029/2012GL052335, 2012.

Large, W. G. and Yeager, S. G.: The global climatology of an interannually varying air-sea flux data set, Clim. Dynam., 33, 341364, https://doi.org/10.1007/s00382-008-0441-3, 2009.

Laxenaire, R., Speich, S., Blanke, B., Chaigneau, A., Pegliasco, C., and Stegner, A.: Anticyclonic Eddies Connecting the Western Boundaries of Indian and Atlantic Oceans, J. Geophys. Res., 123, 7651-7677, https://doi.org/10.1029/2018JC014270, 2018.

Le Bars, D., Dijkstra, H. A., and de Ruijter, W. P. M.: Impact of the Indonesian Throughflow on Agulhas leakage, Ocean Sci., 9, 773-785, https://doi.org/10.5194/os-9-773-2013, 2013.

Lee, S.-K., Park, W., van Sebille, E., Baringer, M. O., Wang, C., Enfield, D. B., Yeager, S. G., and Kirtman, B. P.: What caused the significant increase in Atlantic Ocean heat content since the mid-20th century?, Geophys. Res. Lett., 38, L17607, https://doi.org/10.1029/2011GL048856, 2011.

Lemarié, F.: NEMO/AGRIF Nesting tools, User's Guide (30 January 2006), available at: http://forge.ipsl.jussieu. fr/nemo/attachment/wiki/Users/SetupNewConfiguration/ AGRIF-nesting-tool/doc_nesting_tools.pdf (last access: 9 July 2019), 2006.

Levitus, S., Boyer, T. P., Conkright, M. E., Brien, T. O., Antonov, J., Stephens, C., Stathoplos, L., Johnson, D., and Gelfeld, R.: NOAA Atlas NESDIS 18, World Ocean Database 1998: Volume 1: Introduction, U.S. Gov. Printing Office, Wash., D.C., 1998.

Loveday, B., Durgadoo, J. V., Reasnon, C. J., Biastoch, A., and Penven, P.: Decoupling of the Agulhas Leakage from the Agulhas Current, J. Phys. Oceanogr., 44, 1776-1797, https://doi.org/10.1175/JPO-D-13-093.1, 2014.

Lübbecke, J., Durgadoo, J., and Biastoch, A.: Contribution of Increased Agulhas Leakage to Tropical Atlantic Warming, J. Climate, 28, 9697-9706, https://doi.org/10.1175/JCLI-D-150258.1, 2015.

Lutjeharms, J. R. E.: The Agulhas Current, Springer, Berlin, Heidelberg, https://doi.org/10.1007/3-540-37212-1, 2006.

Lutjeharms, J. R. E. and Ansorge, I. J.: The Agulhas Return Current, J. Mar. Syst., 30, 115-138, https://doi.org/10.1016/S09247963(01)00041-0, 1997.

Madec, G. and the NEMO team: NEMO ocean engine - version 3.6, Note du Pole de modélisation, Institut Pierre-Simon Laplace (IPSL), 27, 2014

Malan, N., Backeberg, B., Biastoch, A., Durgadoo, J. V., Samuelsen, A., Reason, C., and Hermes, J.: Agulhas Current Meanders Facilitate Shelf-Slope Exchange on the Eastern Agulhas Bank, J. Geophys. Res., 123, 4762-4778, https://doi.org/10.1029/2017JC013602, 2018.

Malan, N., Durgadoo, J. V., A., . B., Reason, C., and Hermes, J.: Multidecadal wind variability drives temperature shifts on the Agulhas Bank, J. Geophys. Res., 124, 3021-3035, https://doi.org/10.1029/2018JC014614, 2019.

Martin, T., Park, W., and Latif, M.: Southern Ocean forcing of the North Atlantic at multi-centennial time scales in the Kiel Climate Model, Deep Sea Res. II, 114, 39-48, https://doi.org/10.1016/j.dsr2.2014.01.018, 2015.

Matthes, K., Biastoch, A., Wahl, S., Harlaß, J., Brücher, T., Drews, A., Ehlert, D., Getzlaff, K., Krüger, F., Martin, T., Park, W., Rath, W., Scheinert, M., Schwarzkopf, F. U., Bayr, T., and Schmidt, H.: The Flexible Ocean Climate Infrastructure (FOCI): Mean State and Variability, Geosci. Model Dev., in preperation, 2019.

McWilliams, J. C.: Submesoscale currents in the ocean, Proc. R. Soc. A, 472, 2189, https://doi.org/10.1098/rspa.2016.0117, 2016.

Meinen, C. S., Speich, S., Piola, A. R., Ansorge, I., Campos, E., Kersalé, M., Terre, T., Chidichimo, M. P., Lamont, T., Sato, O. T., Perez, R. C., Valla, D., Berg, M., Le Hénaff, M., Dong, S., and Garzoli, S. L.: Meridional Overturning Circulation Transport Variability at $34.5^{\circ} \mathrm{S}$ During 20092017: Baroclinic and Barotropic Flows and the Dueling Influence of the Boundaries, Geophys. Res. Lett., 45, 4180-4188, https://doi.org/10.1029/2018GL077408, 2018.

Molines, J.-M., Barnier, B., Penduff, T., Brodeau, L., Treguier, A., Thetten, S., and Madec, G.: Definition of the global 1/2 experiment with interannual forcing, ORCA05-G50 CORE, LEGI report, LEGI-DRA-1-11-2006, 2006.

Penven, P., Lutjeharms, J., and Florenchie, P.: Madagascar: A pacemaker for the Agulhas Current system?, Geophys. Res. Lett., 33, L17609, https://doi.org/10.1029/2006GL026854, 2006.

Pichevin, T., Nof, D., and Lutjeharms, J.: Why Are There Agulhas Rings?, J. Phys. Oceanogr., 29, 693-707, https://doi.org/10.1175/15200485(1999)029<0693:WATAR>2.0.CO;2, 1999.

Piola, A., Franco, B. C., Palma, E., and Saraceno, M.: Multiple jets in the Malvinas Current, J. Geophys. Res., 118, 2107-2117, https://doi.org/10.1002/jgrc.20170, 2013.

Quartly, G. D., de Cuevas, B. A., and Coward, A. C.: Mozambique Channel eddies in GCMs: A question of resolution and slippage, Ocean Modell., 63, 56-67, https://doi.org/10.1016/j.ocemod.2012.12.011, 2013.

Rayner, D., Hirschi, J. J. M., Kanzow, T., Johns, W. E., Wright, P., Frajka-Williams, E., Bryden, H. L., Meinen, C. S., Baringer, M. O., Marotzke, J., Beal, L., and Cunningham, S. A.: Monitoring the Atlantic meridional overturning circulation, Deep Sea Res. II, 58, 1744-1753, https://doi.org/10.1016/j.dsr2.2010.10.056, 2011.

Renault, L., McWilliams, J. C., and Penven, P.: Modulation of the Agulhas Current Retroflection and Leakage by Oceanic Current Interaction with the Atmosphere in Coupled Simulations, J. Phys. Oceanogr., 47, 2077-2100, https://doi.org/10.1175/JPOD-16-0168.1, 2017.

Richardson, P.: Agulhas leakage into the Atlantic estimated with subsurface floats and surface drifters, Deep Sea Res. I, 54, 13611389, https://doi.org/10.1016/j.dsr.2007.04.010, 2007.

Ridderinkhof, H., van der Werf, P. M., Ullgren, J. E., van Aken, H. M., van Leeuwen, P. J., and de Ruijter, W. P. M.: Seasonal and interannual variability in the Mozambique Channel from moored current observations, J. Geophys. Res., 115, C06010, https://doi.org/10.1029/2009JC005619, 2010.

Rouault, M. J. and Penven, P.: New perspectives on Natal Pulses from satellite observations, J. Geophys. Res., 116, C07013, https://doi.org/10.1029/2010JC006866, 2011. 
Roullet, G. and Madec, G.: Salt conservation, free surface and varying levels: a new formulation for ocean general circulation models, J. Geophys. Res., 105, 23927-23942, https://doi.org/10.1029/2000JC900089, 2000.

Rühs, S., Durgadoo, J., Behrens, E., and Biastoch, A.: Advective timescales and pathways of Agulhas leakage, Geophys. Res. Lett., 40, 3997-4000, https://doi.org/10.1002/grl.50782, 2013.

Rühs, S., Getzlaff, K., Durgadoo, J., Biastoch, A., and Böning, C. W.: On the suitability of North Brazil Current transport estimates for monitoring basin-scale AMOC changes, Geophys. Res. Lett., 42, 8072-8080, https://doi.org/10.1002/2015GL065695, 2015.

Rühs, S., Zhurbas, V., Koszalka, I. M., Durgadoo, J. V., and Biastoch, A.: Eddy diffusivity estimates from Lagrangian trajectories simulated with ocean models and surface drifter data - a case study for the greater Agulhas system, J. Phys. Oceanogr., 48, 175-196, https://doi.org/10.1175/JPO-D-17-0048.1, 2017.

Rühs, S., Schwarzkopf, F. U., Speich, S., and Biastoch, A.: Cold vs. warm water route - sources for the upper limb of the Atlantic Meridional Overturning Circulation revisited in a high-resolution ocean model, Ocean Sci., 15, 489-512, https://doi.org/10.5194/os-15-489-2019, 2019.

Schouten, M. W., de Ruijter, W. P. M., and van Leeuwen, P. J.: Upstream control of Agulhas Ring shedding, J. Geophys. Res., 107, 3109, https://doi.org/10.1029/2001JC000804, 2002.

Schubert, R., F. U. Schwarzkopf, B. B., and Biastoch, A.: Submesoscale Impacts on Mesoscale Agulhas Dynamics, J. Adv. Model. Earth Syst., under revision, 2019.

Schwarzkopf, F. U.: Data supporting: The INALT family - a set of high-resolution nests of the Agulhas Current system within global NEMO ocean/sea-ice configurations, 2019.

Scussolini, P., van Sebille, E., and Durgadoo, J. V.: Paleo Agulhas rings enter the subtropical gyre during the penultimate deglaciation, Clim. Past, 9, 2631-2639, https://doi.org/10.5194/cp-92631-2013, 2013.

Smeed, D., McCarthy, G., Rayner, D., Moat, B., Johns, W. Baringer, M., and Meinen, C.: Atlantic meridional overturning circulation observed by the RAPID-MOCHA-WBTS (RAPIDMeridional Overturning Circulation and Heatflux Array-Western Boundary Time Series) array at 26N from 2004 to 2017, British Oceanographic Data Centre, Natural Environment Research Council, https://doi.org/10.5285/5acfd143-1104-7b58e053-6c86abc0d94b, 2017.

Speich, S., Blanke, B., and Cai, W.: Atlantic meridional overturning circulation and the Southern Hemisphere supergyre, Geophys. Res. Lett., 34, L23614, https://doi.org/10.1029/2007GL031583, 2007.

Steele, M., Morley, R., and Ermold, W.: PHC: A Global Ocean Hydrography with a High-Quality Arctic Ocean, J. Climate, 14, 2079-2087, 2001.

Steinhardt, J., Cléroux, C., Ullgren, J., de Nooijer, L., Durgadoo, J. V., Brummer, G.-J., and Reichart, G.J.: Anti-cyclonic eddy imprint on calcite geochemistry of several planktonic foraminiferal species in the Mozambique Channel, Mar. Micropaleontol., 113, 20-33, https://doi.org/10.1016/j.marmicro.2014.09.001, 2014.

Stewart, K., Hogg, A. M., Griffies, S., Heerdegen, A., Ward, M., Spence, P., and England, M.: Vertical resolution of baroclinic modes in global ocean models, Ocean Modell., 113, 50-65, https://doi.org/10.1016/j.ocemod.2017.03.012, 2017.

Swart, N., Lutjeharms, J., Ridderinkhof, H., , and de Ruijter, W.: Observed characteristics of Mozambique Channel eddies, J. Geophys. Res., 115, C09006, https://doi.org/10.1029/2009JC005875, 2010.

Swingedouw, D., Fichefet, T., Goosse, H., and Loutre, M. F.: Impact of transient freshwater releases in the Southern Ocean on the AMOC and climate, Clim. Dynam., 33, 365-381, https://doi.org/10.1007/s00382-008-0496-1, 2009.

Tim, N., Zorita, E., Schwarzkopf, F. U., Rühs, S., Emeis, K., and Biastoch, A.: The impact of Agulhas leakage on the central water masses in the Benguela upwelling system from a highresolution ocean simulation, J. Geophys. Res., 123, 9416-9428, https://doi.org/10.1029/2018JC014218, 2018.

Tsujino, H., Urakawa, S., Nakano, H., Small, R. J., Kim, W. M., Yeager, S. G., Danabasoglu, G., Suzuki, T., Bamber, J. L., Bentsen, M., Böning, C. W., Bozec, A., Chassignet, E. P., Curchitser, E., Dias, F. B., Durack, P. J., Griffies, S. M., Harada, Y., Ilicak, M., Josey, S. A., Kobayashi, C., Kobayashi, S., Komuro, Y., Large, W. G., Sommer, J. L., Marsland, S. J., Masina, S., Scheinert, M., Tomita, H., Valdivieso, M., and Yamazaki, D.: JRA-55 based surface dataset for driving ocean-sea-ice models (JRA55-do), Ocean Modell., 130, 79-139, https://doi.org/10.1016/j.ocemod.2018.07.002, 2018.

Ullgren, J. E., van Aken, H. M., Ridderinkhof, H., and de Ruijter, W. P. M.: The hydrography of the Mozambique Channel from six years of continuous temperature, salinity, and velocity observations, Deep Sea Res. I, 69, 36-50, https://doi.org/10.1016/j.dsr.2012.07.003, 2012.

van Aken, H. M., Van Veldhoven, A., Veth, C., De Ruijter, W., Van Leeuwen, P., Drijfhout, S., Whittle, C., and Rouault, M.: Observations of a young Agulhas ring, Astrid, during MARE in March 2000, Deep Sea Res. II, 50, 167-195, https://doi.org/10.1016/S0967-0645(02)00383-1, 2003.

van der Werf, P., van Leeuwen, P., Ridderinkhof, H., and de Ruijter, W.: Comparison between observations and models of the Mozambique Channel transport: Seasonal cycle and eddy frequencies, J. Geophys. Res., 115, C02002, https://doi.org/10.1029/2009JC005633, 2010.

van Leeuwen, P., de Ruijter, W., and Lutjeharms, J.: Natal pulses and the formation of Agulhas rings, J. Geophys. Res., 105, 64256436, https://doi.org/10.1029/1999JC900196, 2000.

van Sebille, E., Scussolini, P., Durgadoo, J. V., Peeters, F. J., Biastoch, A., Weijer, W., Turney, C., Paris, C. B., and Zahn, R.: Ocean currents generate large footprints in marine palaeoclimate proxies, Nat. Commun., 6, 6521, https://doi.org/10.1038/ncomms7521, 2015.

Webb, D. J., De Cuevas, B. A., and Richmond, C. S.: Improved advection schemes for ocean models, J. Atmos. Ocean. Technol., 15, 1171-1187, https://doi.org/10.1175/15200426(1998)015<1171:IASFOM>2.0.CO;2, 1998.

Whitworth, T. and Peterson, R. G.: Volume Transport of the Antarctic Circumpolar Current from Bottom Pressure Measurements, J. Phys. Oceanogr., 15, 810-816, https://doi.org/10.1175/15200485(1985)015<0810:VTOTAC>2.0.CO;2, 1985.

Zalesak, S. T.: Fully multidimensional flux-corrected transport algorithms for fluids, Journal of Computational Physics, 31, 335362, https://doi.org/10.1016/0021-9991(79)90051-2, 1979. 